\title{
II. Vom Sohlbergkreis zur Reichsjugendführung
}

\section{Im Sog der „nationalen Erneuerung“: Gleichschaltung der Jugendverbände}

„Es ist soweit", notierte ein überglücklicher Joseph Goebbels. „Wir sitzen in der Wilhelmstraße. Hitler ist Reichskanzler. Wie im Märchen!"1 Am 30. Januar 1933 wurde der neue Regierungschef vom greisen Reichspräsidenten v. Hindenburg vereidigt. Die Nationalsozialisten feierten das Ereignis mit lautem Getöse, Berlin glich „einem aufgescheuchten Ameisenhaufen“. 25000 uniformierte Hitler-Anhänger passierten Brandenburger Tor und Reichskanzlei, um ihrem ,Führer' Reverenz zu erweisen. In einem „sinnlosen Taumel der Begeisterung“ endete die „Nacht des großen Wunders" 2 .

Der totalitäre Anspruch der braunen Machthaber brach sich umgehend Bahn. Auf dem Weg zur Alleinherrschaft veränderten sie die bestehenden Verhältnisse ebenso rasch wie tiefgreifend. Politische Gegner wurden mundtot gemacht oder ins Exil gejagt, die demokratischen Institutionen der Weimarer Republik und die verfassungsmäßigen Grundrechte Schlag auf Schlag außer Kraft gesetzt, Parlamentarismus, Parteien und Gewerkschaften beseitigt, Länder und gesellschaftliche Organisationen gleichgeschaltet, öffentliche Meinung und Kultur zensiert. Im Zuge dieser Umwälzung stützten sich die Nationalsozialisten auf staatsstreichartige, einen permanenten Ausnahmezustand begründende Verordnungen und Gesetze, die scheinlegale Handhaben für die Usurpation der Staatsgewalt, die Errichtung der Diktatur und verschärften Terror gegen Mißliebige und Oppositionelle boten. Bei alldem fand Hitler durchaus die Zustimmung breiter Schichten, die er mit Versprechungen, populistischen Maßnahmen, suggestiver Rhetorik, bald auch mit tatsächlichen oder vorgeblichen politischen und wirtschaftlichen Erfolgen mobilisierte und für sich vereinnahmte ${ }^{3}$.

Dem gängigen Muster der Machteroberung entsprach die Auflösung und Gleichschaltung der Jugendverbände. Bei dezidiert völkischen und manchen pro-

1 Fröhlich (Hrsg.), Goebbels-Tagebücher, I, 2, S. 357 (Eintrag vom 31. 1. 1933).

2 Ebenda, S. 359, 361. Vgl. Fest, Hitler, S. 507.

3 Aus der Fülle der Literatur über die einzelnen Stufen der, Machtergreifung und die Anfänge des totalitären Maßnahmenstaates siehe die grundlegende Darstellung von Bracher/ Sauer/Schulz, Die nationalsozialistische Machtergreifung; Schulz, Deutschland seit dem Ersten Weltkrieg, S. 117-138; Broszat, Der Staat Hitlers; ders./Möller (Hrsg.), Das Dritte Reich; Frei, Der Führerstaat, S. 38-85; Matthias/Morsey (Hrsg.), Das Ende der Parteien 1933; Höhne, Die Machtergreifung; Jäckel, Hitlers Herrschaft, Kap. 2. Zur Strategie der Koppelung „revolutionärer Überrumpelung mit Akten juristischer Sanktionierung “ auch Fest, Hitler, S. $533 \mathrm{ff}$. Die wichtigsten Gesetzestexte in Auszügen bei Hofer, Nationalsozialismus, S. $55 \mathrm{ff}$. 
testantischen Gruppen verursachte das wenig Aufwand, da sie in ihrer Denkweise und Gefühlswelt der neuen Staatsdoktrin nahe genug standen, um sich bereitwillig einzuordnen ${ }^{4}$. „Ein Jämmerling wäre jeder junge deutsche Mann, der in diesen Tagen gleichgültig mit den Händen in der Tasche dem zuschaut, was um ihn herum geschieht, statt daß er mit ganzem Herzen an dem Aufbruch der Nation teilnimmt", heißt es in einem Aufruf evangelischer Jungmänner" ${ }^{5}$ Konfliktträchtiger gestaltete sich das Verhältnis zur bündischen Jugend bürgerlicher Abkunft. Dabei opponierten viele Bündische kaum ernsthaft gegen den Nationalsozialismus, zu dem es weltanschauliche Berührungspunkte gab. Auch in ihren Kreisen spielten Begriffe wie Reich, Führung und Gefolgschaft eine zentrale Rolle, wurde großdeutsch, antirepublikanisch, antiliberal und häufig judenfeindlich gedacht, nährte der Regimewechsel Hoffnungen, Klassenkampf und politischen Partikularismus, das ganze ,morsche System von gestern' zugunsten einer ständisch gegliederten ,Volksgemeinschaft ${ }^{`}$ überwinden zu können - im Bürgertum insgesamt verbreitete Leitvorstellungen, die ungeachtet gewichtiger inhaltlicher Unterschiede zur NS-Ideologie ein Aufgehen in der jugendbetont und sendungsbewußt agierenden Hitlerpartei begünstigten ${ }^{6}$. Anderseits kämpften die Bündischen um das Recht auf eigene Lebensgestaltung; sie stießen sich an militanter Intoleranz und rohem Gesinnungsterror der NSDAP, die innere Freiheit durch unbedingten Gehorsam, persönliche Verantwortung durch starren Fanatismus, elitäre Kleingruppe durch Massenerfassung, Verbundenheit durch Uniformität ersetzten. Ihr Streben nach Autonomie erwies sich indes als unvereinbar mit den totalitären Ansprüchen der HJ. Die 1926 gegründete Parteijugend, bis 1933 eine Organisation unter vielen, nun mit geballter Staatsmacht im Rücken, forderte kompromißlos das Monopol in der Jugendarbeit. Ihre Strategen, allen voran Baldur v. Schirach, lockten mit der Vision einer geeinten, die nationale Erhebung vollendenden Staatsjugend und proklamierten einen "rücksichtslosen Kampf" gegen die Bünde, deren Zersplitterung angeprangert und denen jede weitere Existenzberechtigung abgesprochen wurde ${ }^{7}$.

Am 8. März 1933, drei Tage nach den Reichstagswahlen, die Hitlers Regierungsgewalt festigten, wichen fünf prominente Führer der „Deutschen Freischar“ (DF) und der „Schlesischen Jungmannschaft" dem wachsenden Druck, erklärten ihren Eintritt in die NSDAP und äußerten öffentlich die Erwartung, „daß die deutsche bündische Jugend sich nach unserem Beispiel dem Gebot der Stunde

4 Hierzu Klönne, Jugendbewegung und Faschismus, S. 25 ff.; Brandenburg, Geschichte der HJ, S. 98 ff., 139 ff.; Giesecke, Vom Wandervogel bis zur Hitlerjugend, S. $187 \mathrm{f}$.

5 Zit. bei Priepke, Evangelische Jugend, S. 46.

6 Zur Diskussion über ideologische Affinitäten zwischen Jugendbewegung und Nationalsozialismus, auch zum Folgenden siehe Stachura, Deutsche Jugendbewegung und Nationalsozialismus, S. 35-52; Kater, Bürgerliche Jugendbewegung und Hitlerjugend, S. 127174; v. Hellfeld, Bündische Jugend und Hitlerjugend, S. $57 \mathrm{ff}$., 73 f., $211 \mathrm{ff}$.; Brandenburg, Geschichte der HJ, S. 67f.; Giesecke, Vom Wandervogel bis zur Hitlerjugend, S. $94 \mathrm{ff}$., $180 \mathrm{f}$.; Jovy, Jugendbewegung und Nationalsozialismus; Bleuel/Klinnert, Deutsche Studenten, S. $41 \mathrm{ff}$.

7 Vgl. v. Schirach, Hitler-Jugend, bes. S. 34, $48 \mathrm{ff} ., 69$. 
nicht versagt" ${ }^{\text {"8 }}$. Ein Akt mit Signalwirkung, denn unmittelbare Gefahr war nicht im Verzug gewesen, und die vergleichsweise liberale DF, mit rund 12000 Mitgliedern der bedeutendste Zusammenschluß von Bündischen, hatte rechtsextremistischen Avancen seither weitgehend widerstanden und sich um positive Mitarbeit im Weimarer Staat bemüht ${ }^{9}$. Weitere Ergebenheitsadressen an die neuen Machthaber folgten, wenn auch der Anspruch auf Selbstbestimmung zumindest verbal aufrechterhalten wurde. Am 5. April stürmte ein bewaffneter HJ-Trupp unter Führung von Schirachs Stellvertreter Carl Nabersberg die Berliner Geschäftsstelle des Reichsausschusses der deutschen Jugendverbände, suspendierte den Vorstand und beschlagnahmte Vermögenswerte und umfangreiche Unterlagen. Das widerrechtliche Vorgehen blieb ungesühnt und ermunterte nur zu weiteren Überfällen und anderen Schikanen. Als Schirach am 17. Juni zum ,Jugendführer des Deutschen Reiches' ernannt wurde, verfügte er unverzüglich die Auflösung des Reichsausschusses und des "Großdeutschen Bundes“, den autonome Bünde zwischenzeitlich zur kollektiven Selbstbehauptung gebildet hatten. In der Folge kapitulierten immer mehr Gruppierungen, traten der $\mathrm{HJ}$ und dem Jungvolk zum Teil geschlossen bei, lösten sich aus Protest selber auf oder wurden verboten und in die Illegalität gedrängt. Lediglich katholische Verbände vermochten sich im Schutz des Konkordats noch einige Zeit zu halten ${ }^{10}$. Die mit dem Regime kooperierten, ließen sich nicht selten vom Sog der "nationalen Erneuerung“ mitreißen, wähnten den stets erstrebten gesellschaftlichen Aufbruch für gekommen, handelten häufig aber auch aus Furcht, Opportunismus oder in der Erwartung, durch demonstrative ideologische Nähe etablierte Freundeszirkel, einen Rest an Autonomie und eigene Zielsetzungen bewahren zu können. $\mathrm{Da} ß \mathrm{HJ}$ und Jungvolk, lawinenartig angewachsen, enormen Bedarf an qualifiziertem Führungspersonal hatten, schien Chancen der Einwirkung zu eröffnen und nährte ebenso wie die Übernahme zahlreicher bündischer Rituale und Gesellungsformen Hoffnungen, daß es gelingen würde, bündischen Geist zu tradieren.

Auch Otto Abetz wurde von dieser dramatischen Entwicklung erfaßt und gezwungen, sein Verhältnis zum NS-Regime zu definieren. Im Staat des notorischen Franzosenfeindes Hitler drohte ihm Ungemach. Fast wäre er ein Opfer jener politischen Säuberungen geworden, mit denen die Nationalsozialisten gewaltsam jede oppositionelle Regung auszumerzen trachteten. Kaum hatte die Reichsregierung, gestützt auf die sogenannte Reichstagsbrandverordnung, am 8. März 1933 den badischen Landtagsabgeordneten und Gauleiter Robert Wagner als Reichskommissar eingesetzt, ihn zur "Wahrnehmung der Befugnisse der obersten Landesbehörde" ermächtigt und damit das Signal zum Umsturz im Südwesten gegeben ${ }^{11}$, erschienen NS-Kommissare zu einer Sitzung der Arbeitsgemeinschaft Karlsruher Jugendbünde und erklärten Abetz unmißverständlich, er genieße nicht

\footnotetext{
8 Zit. nach Paetel, Jugendbewegung und Politik, S. 124.

9 Vgl. Brandenburg, Geschichte der HJ, S. 68 f.

$10 \mathrm{Vgl}$. Raabe, Bündische Jugend, S. 167 ff.; Thamer, Verführung und Gewalt, S. $402 \mathrm{ff}$. Die evangelischen Verbände wurden mit Hilfe des Reichsbischofs Müller eingegliedert.

11 Vgl. Ott, Das Land Baden im Dritten Reich, in: Badische Geschichte, S. $184 \mathrm{ff}$.; Hug, Geschichte Badens, S. $335 \mathrm{ff}$.
} 
das Vertrauen der neuen Machthaber. Sein Einwand, die HJ sei von ihm stets genauso unparteiisch behandelt worden wie alle anderen Gruppen, fruchtete nichts. Er wurde als „Pazifist“ und „Französling" beschimpft und seines Amtes enthoben $^{12}$.

Nicht zuletzt zwei im Februar veröffentlichte Aufsätze aus seiner Feder hatten ihn gefährlich in Mißkredit gebracht. In der Deutsch-französischen Rundschau bemühte er sich, der verschärften inhaltlichen Polarisierung bei den Sohlbergkongressen entgegenzuwirken und die ursprüngliche Begeisterung neu zu entfachen. Die Zukunft der bilateralen Jugendbeziehungen liege nicht in Diskussionen über unterschiedliche Wesensart und Vergangenheit, sondern im „gemeinschaftlichen Erarbeiten neuer Lebensinhalte und neuer Lebensformen“. Es gelte „die Grundlagen zu suchen und zu festigen, welche das heute so zerrissene Abendland zu einem politisch, wirtschaftlich und kulturell gesunden Staatenblock machen, der Asien und Amerika gewachsen ist". Entschieden wandte er sich gegen eine einseitig ostwärts gerichtete Orientierung des Reiches und verknüpfte diesen Standpunkt geschickt mit einem Appell an Frankreich, seinen deutschlandpolitischen Kurs zu korrigieren: „Es liegt nur an dem, daß Frankreich und die von ihm aufrechterhaltene politische und wirtschaftliche Ordnung dem hungernden, arbeitslosen und in seinem nationalen Stolz verletzten Jugendlichen Mitteleuropas keine Lösungen zu bieten oder zu versprechen hat. Der Tag, der den schöpferischen, formkräftigen Genius der französischen Nation auf den Plan ruft, um mutig und vorurteilslos an der europäischen Neuordnung mitzuarbeiten, wird auch die Einheitsfront der deutschen und französischen Jugend sehen. Nicht Verschiedenheit der Wesensart, sondern das andere politisch-wirtschaftliche Schicksal und die Unkenntnis der gemeinsamen Aufgaben stehen heute dem Kontakt im Wege." Deutschlands Jugend sehe sich „nicht zwischen West und Ost, sondern an der Seite der französischen mit West und Ost vor Europa"13. In einem Beitrag für Notre Temps schilderte Abetz die Bündische Jugend als unerschütterlich unabhängige Kraft, gegen deren erklärten politischen Willen kein Reichskabinett regieren könne. Allein die nach Mitgliedern recht kompakte „Deutsche Freischar“ vermöge die Haltung der gesamten deutschen Jugend stärker zu beeinflussen als irgendeine Massenorganisation. Er entwickelte das auf Freiwilligkeit basierende Führer-Gefolgschaftsverhältnis unter Jugendbewegten - „trop précieuse pour être remplacée par le ,drill' d'avant-guerre" - und erklärte die bündische Autonomie zur Grundvoraussetzung einer Mitarbeit im Reichskuratorium für Jugendertüchtigung, „sous condition qu'il reste fidèle à son programme sportif“. Das waren provokante, nachgerade dreiste Töne in nationalsozialistischen Ohren, die den totalitären Gestaltungswillen der Braunhemden völlig zu ignorieren schienen,

12 Zuvor widersetzte sich Abetz, eigenen Angaben zufolge, noch der Forderung, den protestantischen Jugendpfarrer Kappes, der im Wahlkampf couragiert gegen Wagner aufgetreten war, unverzüglich des Versammlungsraumes zu verweisen. „Curriculum vitae" vom 16. 11. 1945, pag. 5; AN, F 7/15331. Vernehmungsprotokoll vom 28. 5. 1947, pag. 1; StA Nürnberg, KV-Anklage, Interrogations, A 2. Abetz, Das offene Problem, S. 34f.; Befragung Bran, 18. 3. 1989.

13 Abetz, Deutsche Jugend zwischen West und Ost, in: DFR 6 (1933), S. 128-132. 
Luchaire hingegen zu dem beruhigenden Hinweis an seine Leser veranlaßten, der Artikel zeige, daß es ungerecht wäre, Leibeserziehung in Deutschland automatisch mit vormilitärischer Ausbildung gleichzusetzen, gegen die sich Widerstände im Reich selber formierten ${ }^{14}$.

Wie der damalige HJ-Gebietsführer in Baden, Friedhelm Kemper, später bezeugte, hatte er aus Berlin Weisung erhalten, Abetz festnehmen und in ein Konzentrationslager verbringen zu lassen, dies jedoch abgelehnt ${ }^{15}$. Anders als die ortsfremden NS-Kommissare, die den AKJ-Vorsitzenden ohne Umschweife maßregelten, war er Abetz, der ihn zu Veranstaltungen des Sohlbergkreises einzuladen pflegte, offenbar gewogen ${ }^{16}$. Überhaupt zahlte es sich in jenen unsicheren Monaten, $\mathrm{da}$ willkürliche Verhaftungen und Drangsalierungen an der Tagesordnung waren, für den zur Renitenz neigenden Abetz aus, daß er stets gute Beziehungen zur Karlsruher HJ unterhalten und sich wiederholt für sie eingesetzt hatte. 1927, soeben zum Leiter der AKJ gewählt, drückte er die Aufnahme des Nationalsozialistischen Schülerbundes durch, der die Einrichtungen der Arbeitsgemeinschaft fortan gleichberechtigt nutzen durfte ${ }^{17} .1929$ protestierte er gegen das vom sozialdemokratischen Innen- und Kultusminister Remmele verhängte Verbot der Hitlerjugend an Badens Schulen, einem zentralen Feld nationalsozialistischer Penetration ${ }^{18}$. Nachdem sein Antrag, die AKJ möge geschlossen gegen das Verdikt intervenieren, am Veto linker und konfessioneller Gruppen gescheitert war, will er

14 Ders., L'orientation actuelle de la Jeunesse allemande, in: Notre Temps, 26. 2. 1933, Sp. 395-399. Die durch Erlaß Hindenburgs vom 13. September 1932 verfügte Gründung des Reichskuratoriums für Jugendertüchtigung, von Kritikern als Tarninstrument beargwöhnt, sollte den Plänen der Reichswehrführung dienen, die Tätigkeit der diversen Wehrjugendverbände unter staatlicher Aufsicht zusammenzufassen, die Heranwachsenden einer systematischen paramilitärischen Schulung zu unterziehen, auf diese Weise das Wehrpflichtverbot des Versailler Vertrags zu umgehen und verborgene Reserven zu schaffen. Die Regierung Hitler konnte an diese und andere Vorarbeiten zur psychologisch-propagandistischen Mobilmachung der Bevölkerung anknüpfen. Vgl. Wolfram Wette, Ideologien, Propaganda und Innenpolitik als Voraussetzungen der Kriegspolitik des Dritten Reiches, in: Deist u.a., Ursachen und Voraussetzungen, S. $145 \mathrm{f}$.; Wortmann, Baldur von Schirach, S. $96 f ., 104 f$.

15 Eidesstattliche Erklärung Kempers vom 7. 8. 1949, abgedruckt in: Scheinwerfer 2 (1949), Nr. 19, S. 9. A betz erwähnt den Vorgang in seinen Memoiren und datiert ihn ungefähr auf Ende April 1933, nach seiner Rückkehr vom deutsch-französischen Jugendtreffen in Paris; Das offene Problem, S. 38.

16 „Otto Abetz unterhielt zu mir gute Beziehungen. Er stand bei vielen Auseinandersetzungen auf meiner Seite.“ Darstellung Kempers vom Januar 1978, „Meine Begegnungen mit Otto Abetz ${ }^{\text {“ }}$, abgedruckt in: Rüdiger (Hrsg.), Hitler-Jugend, Anhang Abb. 60. Biographische Einzelheiten zu Kemper, Jg. 1906, NSDAP-Mitglied seit 1923 und Wagner-Intimus, bei Bräunche, Die Entwicklung der NSDAP in Baden bis 1932/33, S. 342; Grill, The Nazi Movement in Baden, S. $216 \mathrm{ff}$., 314f., 338f. Laut Hug, Geschichte Badens, S. 341, machte Kemper als HJ-Funktionär eine "gewinnende Figur".

17 Im selben Jahr schickte sich die NSDAP in Baden an, das Image einer bedeutungslosen Splitterpartei abzustreifen. Bei der Reichstagswahl 1928 erzielte sie 2,9\% und lag damit bereits über dem Reichsdurchschnitt (September 1930: 19,2\% gegenüber 18,3\% im Reichsmittel). Diese Zahlen nach Hug, Geschichte Badens, S. 327.

18 Vgl. Bräunche, Entwicklung der NSDAP, S. 353; Verhandlungen des Badischen Landtags, 1. Session 1929/30, Beilagenheft, Dok. 66. 
sogar persönlich bei seinem obersten Dienstherrn vorstellig geworden sein, obgleich er "noch nicht einmal im planmäßigen Beamtenverhältnis stand "19. 1932 schließlich trat er in Kontakt mit Leopold Plaichinger, einem außenpolitisch ambitionierten Parteiveteranen mit direktem Draht nach München, Mitarbeiter von Hitlers Wirtschaftsberater Wilhelm Keppler in den Eberbacher Odin-Werken und eine bekannte Parteigröße in Nordbaden ${ }^{20}$. Bei einer Unterredung im Juni soll es bereits um die Auswertung der Frankreichbeziehungen des Sohlbergkreises für die NSDAP gegangen sein ${ }^{21}$. Wiewohl sich sämtliche Angaben näherer Überprüfung entziehen und zu berücksichtigen ist, daß sie Abetz Jahre später während eines SS-Ehrengerichtsverfahrens entlasten sollten, mithin naheliegt, daß er eher übertrieb, um seine Linientreue hervorzuheben ${ }^{22}$, entbehren sie doch nicht gänzlich der Glaubwürdigkeit. Weder die nach jugendbewegter Tradition praktizierte Überparteilichkeit in der AKJ noch das geistige Marschgepäck etlicher Mitglieder und Sohlbergsympathisanten gestatteten eine energische Abgrenzung gegen extremistische Kräfte. So vermittelte Friedhelm Kemper um die Jahreswende 1933/ 34 entscheidende Gespräche für Abetz' Mitwirken in der Reichsjugendführung 23 . Zu den Kontaktpersonen soll auch ein gewisser Graf Mirbach-Geldern gehört haben, der nachweislich der kleinen Delegation des Sohlbergkreises angehörte, die nach zähen Verhandlungen mit der Reichsdiplomatie im April 1933 nach Paris fuhr ${ }^{24}$. Dank dieser Querverbindungen und mit einem tüchtigen Schuß Zivilcourage konnte einstweilen sowohl die Arbeit des Sohlbergkreises weitergeführt als auch der eine oder andere Ärger mit der Geheimpolizei ausgestanden werden. Die Gestapo, so Abetz nach dem Krieg, habe wegen Verbreitung französischer Zeitschriften gegen ihn ermittelt und ihm Spionagetätigkeit vorgeworfen, als ein französischer Gast, der Pariser Filmschaffende Gabriel Monod-Herzen, im Sommer 1933 Aufnahmen von einem HJ-Lager im Schwarzwald machen wollte ${ }^{25}$.

19 Abetz an John, 1. 9. 1937; Lebenslauf vom 23. 8. 1937; BDC/Abetz. Laut Lebenslauf wurde er 1932 als Assessor für das künstlerische Lehramt verbeamtet.

20 Grill, Nazi Movement in Baden, S. 155f.

21 Abetz an John; desgleichen in seiner Aufzeichnung „zum Vorwurf, vor der Machtergreifung aktiver Gegner des Nationalsozialismus gewesen zu sein“; BDC/Abetz. Der 1889 in Österreich geborene Plaichinger, von Beruf Chemiker, erlag im Februar 1933 einem Lungenleiden.

22 Zwingend in diese Richtung weisen seine - im nachhinein schwer widerlegbaren - Argumente von 1937, er habe als Gymnasiallehrer „stets den Kunstbolschewismus bekämpft ${ }^{*}$, alle großen Kundgebungen der NSDAP in Karlsruhe besucht und sich an einer Protestaktion der $\mathrm{HJ}$ gegen die Aufführung eines Theaterstücks eines jüdischen Autors beteiligt. Abetz an John, ebenda.

23 Vgl. Kemper, "Meine Begegnungen mit Otto Abetz“.

24 Vgl. das deutschsprachige Kommuniqué der Tagung in PA/AA, Botschaft Paris 1050/1.

25 „Curriculum vitae“, pag. 6; AN, F 7/15331. Detaillierter hinsichtlich des ersten Vorfalls, knapper zum Vorgang Monod-Herzen Das offene Problem, S. 38. Monod-Herzen gehörte zum Freundeskreis von Notre Temps. Probleme mit der Gestapo deutete Abetz auch bei seiner Zeugenaussage im Luchaire-Prozeß an: „J'ai risqué plus d'une fois d'être arrêté ${ }^{\alpha}$; Les procès de collaboration, S. 489. 


\section{Vom "wahren Charakter" der Hitlerbewegung: Begegnungen in Paris (1933) und Berlin (1934)}

Abetz' Tatendrang war ungebrochen: „Ich vertrat [...] den Standpunkt, daß meine Abberufung von der Leitung der Arbeitsgemeinschaft Karlsruher Jugendbünde die in meiner Hand liegende Leitung des Sohlbergkreises nicht berühre, und setzte diese Tätigkeit unverändert fort. Insbesondere betrieb ich die Vorbereitungen zur deutsch-französischen Jugendtagung, die für Ostern 1933 in Paris vereinbart war. ${ }^{26}$ Die Art und Weise, wie er hierbei um enge Abstimmung mit den zuständigen Behörden rang, verrät einmal mehr den Taktiker, der hartnäckig seine Vorstellungen verficht und zugleich nach Rückversicherung strebt, darüber hinaus ein hohes Maß von Anpassungsbereitschaft an das NS-Regime und sicheren Instinkt, welche Argumente in Anbetracht der gewandelten politischen Verhältnisse verfangen würden. Von einem "Waffengang" mit dem Auswärtigen Amt, den seine Memoiren suggerieren ${ }^{27}$, kann nach Aktenlage jedoch nur beschränkt die Rede sein. Die Diplomaten agierten passiv, hielten sich ob des weitgehend ungeklärten außenpolitischen Kurses der Regierung Hitler bedeckt, vermochten den offenkundig als lästig empfundenen Karlsruher Organisator, der überdies finanzielle Hilfe beantragt hatte, jedenfalls nicht abzuschütteln. Mit Bezug auf Roland Kösters Brief an Bran vom Dezember 1932, der „zu unserer lebhaften Freude“ wohlwollendes Interesse am Sohlbergkreis signalisiere, bat Abetz die Pariser Botschaft Ende Februar um "Beratung und Unterstützung", entwickelte sein Vorhaben und problematisierte es zielgerichtet. Geplant sei ein vom 15. bis 21. April dauernder Kongreß über das „Staatsbild des jungen Deutschland und Frankreich“, ein mit Bedacht gewähltes Motto, das es ermögliche, „den Franzosen Unverständliches in der jüngsten deutschen Entwicklung, die Staats- und Volksidee des neuen deutschen Nationalismus, den Einsatz der Bünde für Arbeitsdienst, Wehrsport und Werkjahr" zu erläutern. In diesen Zusammenhang könnten selbst „die aktuellsten politischen Fragen und die deutsche Stellungnahme zu ihnen auf das Beste" eingebettet werden ${ }^{28}$. Die werbend herausgekehrte Zuversicht wurde in der Rue de Lille jedoch keineswegs geteilt. Mit Bleistift notierte Botschafter Köster seine Zweifel auf den Briefrand: „Ist sich der Sohlbergkreis über die Entwicklung und die Staats- und Volksidee des neuen deutschen Nationalismus, besonders aber über die weitere Entwicklung dieses Nationalismus vollkommen im Klaren?" Die Formulierung „auf das Beste“ erntete ein skeptisches „?!“. Lediglich Abetz' Ankündigung, deutsches Kulturleben durch eine Bücherschau, Lichtbil-

${ }^{26}$ Abetz, Das offene Problem, S. 35. Friedrich Bran erklärte hierzu, er habe damals die Führung des Kreises übernommen, um den politisch mißliebigen Abetz, der unter anderem als Kommunist verleumdet worden sei, ,aus der Schußlinie zu holen“. Am 1. Mai 1933 wurde Bran NSDAP-, am 1. Juni HJ-Mitglied, wenig später Hauptreferent im Auslandsamt der RJF. Befragung Bran, 18. 3. 1989; Unteutsch, Sohlbergkreis, S. 154, $332 \mathrm{f}$.

27 Abetz, Das offene Problem, S. 35.

28 Abetz an Botschaft Paris; PA/AA, Botschaft Paris 1050/1. Das im Original erhaltene Dokument trägt, wie sich aus dem Eingangsstempel „25. II.“ und dem nachfolgenden Schriftverkehr ergibt, fälschlicherweise das Datum 23. März 1933; gemeint war zweifelsfrei der 23. Februar. 
dervorträge und musikalische Darbietungen vorteilhaft zu präsentieren, fand Beifall29. Eine konkrete Darlegung seines eigenen Standpunktes scheute Köster angesichts der Umbruchsituation im Reich. Statt dessen ließ er ausrichten, „daß der Komplex der von Ihnen angeschnittenen Fragen leider für eine Korrespondenz nicht recht geeignet ist. Die Botschaft ist gern bereit, ihn mit Ihnen oder einem Ihrer Herren Mitarbeiter durchzusprechen, möchte aber von schriftlichen Erörterungen Abstand nehmen." Damit einher ging die Empfehlung, sich in dieser Angelegenheit besser an das Berliner Auswärtige Amt zu wenden ${ }^{30}$.

Dort sprach Abetz wenige Tage später vor, wie eine Mitteilung an die Botschaft Paris vom 14. März belegt ${ }^{31}$. In der Wilhelmstraße suchten ihm „distinguierte, im Mienenspiel unbewegliche, durchgeistigte" Herren der Kulturpolitischen Abteilung sein Vorhaben auszureden, mit der stereotypen Begründung, es sei ungewiß, ob die geplante Tagung dem Wollen der neuen Regierung entspreche. Abetz erwiderte - nur von ihm überliefert, aber durchaus typisch für sein aufbrausendes Temperament -, der Sohlbergkreis werde das Treffen in jedem Fall beschicken, notfalls würden seine Mitglieder eben illegal nach Frankreich einreisen ${ }^{32}$. Letztlich waren beide Seiten zu Zugeständnissen bereit. Die Diplomaten, von der Entschlossenheit und den Argumenten des Karlsruhers nicht unbeeindruckt geblieben, verlegten sich darauf, wenigstens den Umfang des Projekts und das erwartete öffentliche Aufsehen einzugrenzen. Abetz für seinen Teil grollte, er habe nur der finanziellen Abhängigkeit wegen eingelenkt ${ }^{33}$. Im Kern hatte er sich allemal behauptet. Man kam überein, den eigentlichen Kongreß auf den Herbst zu verschieben und sich für April mit einer deutsch-französischen Zusammenkunft in kleinem Rahmen zu begnügen, die als „vorbereitende, interne Führerbesprechung“ tituliert wurde ${ }^{34}$. Am darauffolgenden Wochenende eilte Abetz nach Paris, um die geänderte Planung mit den französischen Freunden abzustimmen, was offenbar ohne Schwierigkeiten gelang. Seine Bitte um eine Audienz in der Botschaft wurde erfüllt, in Abwesenheit Kösters empfing ihn Botschaftsrat Forster. Während ihrer Unterredung am 19. März insistierte Abetz, „daß gerade in der gegenwärtigen Zeit alles geschehen müsse, um die bestehenden Fäden aufrechtzuerhalten“. Auch sein maßgeblicher Kontaktmann in Berlin, Legationsrat v. Rintelen, erkenne an, $\mathrm{da} ß$ die nun gefundene Lösung nützliche „Bewegungsfreiheit“ biete und „den Franzosen den Gedanken nehme, daß die Deutschen die Beziehungen ganz abbrechen wollten". Forster bestätigte die Notwendigkeit, das Ausland zu informieren und den reichlich kursierenden "Alarmgerüchten" entgegenzutreten. Er billigte den ausgehandelten Kompromiß, nicht ohne ausdrücklich zu verlangen, die deut-

29 Ebenda, Hervorhebung im Original.

30 Kühn (Botschaft Paris) an Abetz, 3. 3. 1933; PA/AA, Botschaft Paris 1050/1.

${ }^{31}$ Abetz an Botschaft Paris, 14. 3. 1933, ebenda. Eine "schriftliche Vorladung“ (Das offene Problem, S. 35) hat er wohl kaum erhalten; alles deutet darauf hin, daß er sich selber um den Termin bemühte.

32 Abetz, Das offene Problem, S. 35, mit verächtlichem Unterton, den er im Gefühl, ein diplomatischer Avantgardist gewesen zu sein, bei der Charakterisierung von Berufsdiplomaten der alten Schule häufiger anschlug.

33 Aktenvermerk Forster (Paris), 21. 3. 1933; PA/AA, Botschaft Paris 1050/1.

34 Abetz an Forster, 2. 4. 1933, ebenda. 
schen Konferenzteilnehmer müßten „jede Gelegenheit ergreifen [...], den wahren Charakter der Hitlerbewegung und des heutigen Deutschlands" zu erläutern. Auf keinen Fall dürften innenpolitische Kontroversen vor französischem Publikum ausgetragen werden ${ }^{35}$.

Diesen Vorgaben ordneten sich die Sohlbergler bereitwillig unter. Abetz gelobte Forster, nur sichere Kantonisten nach Paris mitzunehmen, von Verbänden, „welche fest auf dem Boden der neuen Regierung stehen“. Die Position der übrigen Jugendorganisationen wolle er persönlich interpretieren, wobei, so seine beschwichtigende Auskunft, hinsichtlich Arbeitsdienst, Jugendertüchtigung und ähnlichem sowieso keine fundamentalen Gegensätze bestünden, sondern nur Meinungsverschiedenheiten in der Führungsfrage. Auch das war meilenweit entfernt von jener vor Selbstbewußtsein strotzenden Präsentation der Bündischen Jugend als mächtigem, auf Unabhängigkeit pochenden Faktor im innerdeutschen Kräftespiel, deren er sich noch wenige Wochen zuvor in Notre Temps befleißigt hatte. Nach Motiven für den auffälligen Kurswechsel wird zu suchen sein; sie versprechen näheren Aufschluß darüber, unter welchen Prämissen er seine Karriere in Diensten des Nationalsozialismus begann. „Breitesten Raum“, versicherte Abetz weiter, „werden natürlich Entgegnungen zur Greuelpropaganda einnehmen; wir wollen eine Sonderbesprechung mit allen uns erreichbaren Redakteuren von Zeitschriften der jungen französischen Generation wegen der künftigen Berichterstattung über die deutschen Verhältnisse ansetzen." Soviel Botmäßigkeit verquickte er geschäftstüchtig mit der Beschwerde, das Auswärtige Amt habe immer noch keinen Zuschuß bewilligt, ohne den kaum einer fahren könne. Jugendführer, die sich bereit fänden, „eine so schwere und unangenehme Arbeit zu tun wie die, welche uns in Paris bevorsteht", dürften gewiß mehr Entgegenkommen erwarten, immerhin gehe es „um eine Sache, deren Nichtzustandekommen viele wertvolle Verbindungen zum jungen Frankreich zerstören würde" ${ }^{\text {"36. Das }}$ saß. Eine Woche später meldete Abetz beglückt, das AA habe $800 \mathrm{RM}$ angewiesen, und gab seiner Hoffnung Ausdruck, die psychologischen Rückwirkungen der Pariser Tagung möchten den finanziellen Aufwand rechtfertigen. Die meisten deutschen Teilnehmer würden sich schon einige Tage im voraus zusammenfinden, um Richtlinien für ein einheitliches Auftreten in Frankreich festzulegen ${ }^{37}$. Statt der ursprünglich vorgesehenen 60köpfigen Delegation passierten schließlich nur sieben Emissäre die Grenze: außer Abetz Graf Mirbach-Geldern („unser nationalsozialistisches ,Renommierstück'“38), Walther Reusch (Deutsche Studentenschaft), Hellmuth Roether (HJ), Dr. Max (Freie Jugendbewegung), Waldemar Kirstein (Jungteutonischer Orden) und Gustav Mittelstraß (Sohlbergkreis) ${ }^{39}$.

\footnotetext{
35 Aktenvermerk Forster, ebenda.

36 Abetz an Forster, 2. 4. 1933, ebenda.

37 Abetz an Forster, 9. 4. 1933. Forster hatte v. Rintelen zwei Tage zuvor eine Abschrift des Abetz-Briefes vom 2. April geschickt „mit dem Anheimstellen, sich seiner Wünsche anzunehmen"; ebenda.

38 Abetz, Das offene Problem, S. 37.

39 Wie Anm. 24.
} 
In Paris bekamen sie zu spüren, wie sehr die nationalsozialistische Machteroberung die Gemüter beschäftigte. Der ,Führer hatte eine denkbar schlechte Presse, noch waren seine Hetztiraden und Racheschwüre in allzu frischer Erinnerung. Von besorgter Ratlosigkeit bis hin zu lautstarken Protesten gegen gewalttätige Auswüchse des NS-Regimes reichte die Bandbreite der Reaktionen. Viele Franzosen glaubten damals, was sie später nicht mehr wahrhaben wollten: Hitler bedeutet Krieg ${ }^{40}$. „Seit vier Wochen werden täglich fast zehntausend Fragen an mich gestellt", berichtete der Korrespondent der Frankfurter Zeitung, Friedrich Sieburg, Anfang April. „Sie richten sich wie Gewehrläufe gegen meine Brust, ihre Zahl und Heftigkeit ist in den letzten acht Tagen so gewachsen, daß man über Engelszungen verfügen müßte, um auch nur einen Bruchteil von ihnen zu beantworten." Wer aber seiner patriotischen Pflicht genüge und den Umschwung in Deutschland verteidige, wer darauf verzichte, „ihn als einen Sieg niedriger Mächte oder einen Akt kollektiven Wahnsinns zu bezeichnen", sei in den Augen etlicher Franzosen fast zwangsläufig ein Agent Adolf Hitlers. Auch ihn, Sieburg, habe man bereits bezichtigt, mit vollem Gepäck ins Lager der Mörder übergewechselt zu sein, obwohl er lediglich das Recht in Anspruch nehme, sein Land um jeden Preis zu lieben ${ }^{41}$. Anwürfe dieses Kalibers blieben Abetz und seinen Begleitern vorerst erspart - sie sahen sich in Paris bestaunt "wie Wundertiere" und konfrontiert mit einer unübersichtlichen Gemengelage aus Neugier, Ablehnung und bemühter Unvoreingenommenheit. Etwa 30 Franzosen beteiligten sich an der zweitägigen Konferenz (21./22. April), die in den Redaktionsräumen von Notre Temps tagte, zu einem Gutteil Mitarbeiter der Zeitschrift und altbekannte Repräsentanten von linksgerichteten und katholischen Jugend- und Studentenverbänden. Hinzu gesellten sich einige von der Entwicklung in Deutschland elektrisierte Beobachter, unter ihnen Alfred Fabre-Luce, wie Bertrand de Jouvenel ein wirtschafts- und außenpolitischer Vordenker der jungradikalen Bewegung in den zwanziger, nach rechts driftender zeitweiliger Parteigänger Doriots in den dreißiger Jahren ${ }^{42}$, und der spätere intellektuelle Kollaborateur Pierre Drieu La Rochelle, der 1928 in seinem Buch Genève ou Moscon für ein föderales Europa plädiert hatte ${ }^{43}$. Ziel der Zusammenkunft war es, so ein gemeinsam veröffentlichtes Kommuniqué, „de rétablir le contact entre les mouvements de jeunesse en Allemagne et en France - contact relâché, affaibli par les récents événements politiques". Betont wurde der strikt private Charakter des Treffens, ein Hinweis, daß die Organisatoren in An-

40 Zur überwiegend düsteren Stimmungslage Kimmel, Aufstieg des Nationalsozialismus, S. $152 \mathrm{ff}$. Seinen Recherchen zufolge befürchteten französische Mitte-Links-Kreise 1933, eine „Politik des bewaffneten Friedens“ einschlagen zu müssen, die schon 1914 den Krieg nicht verhindert hatte. Scharf antideutsch eingestellte Nationalisten werteten den Nationalsozialismus als neue, bedrohliche Variante des Pangermanismus. Allen Richtungen gemein war anfänglich die Forderung nach "fermeté ${ }^{\text {, }}$, das heißt einer nationalsozialistischen Regierung sollten keine vorschnellen Konzessionen gemacht werden.

41 Sieburg, Persönliches und etwas mehr. Von den Pflichten des Auslandsdeutschen, in: Frankfurter Zeitung und Handelsblatt, 9. 4. 1933, Abendblatt/Erstes Morgenblatt.

42 Vgl. Sick, Vom Neoliberalismus zum Faschismus?, S. 59-75; Burrin, La dérive fasciste, S. $79 \mathrm{ff}$.

43 Vgl. Andreu/Grover, Drieu La Rochelle, S. 214 f.; Burrin, S. $91 \mathrm{ff}$. 
betracht der aufgewühlten Stimmung im Lande unnötiges Aufsehen und den Eindruck allzu ausgedehnter Beziehungen zur nationalsozialistischen Jugend vermeiden wollten ${ }^{44}$.

Die Gäste deuteten die jüngsten Ereignisse in Deutschland, im Einklang mit der NS-offiziellen Lesart, als noch in vollem Gang befindliche nationale Revolution, in ihrer Tragweite vergleichbar den Umwälzungen von 1789 und 1917, die sich bekanntlich auch nicht ohne Gewalt, Einschränkung von Persönlichkeitsrechten und patriotischen Überschwang vollzogen, sondern im Gegenteil einen viel höheren Blutzoll gefordert hätten. Der Grundsatz Gemein- vor Eigennutz verlange einschneidende Maßnahmen, nicht zuletzt gegen die Juden, deren stark überproportionaler Einfluß in Politik, Wirtschaft und Kultur eine unsichtbare Unterdrückung („oppression invisible“) der Bevölkerung bewirkt habe. Sobald das Regime gefestigt sei, würden sich die Verhältnisse normalisieren. Schon heute könne sich „aufbauwillige Kritik“ ungehindert entfalten, mit der jüdischen Minderheit werde man einen achtbaren Modus vivendi finden. Letzteres lag den französischen Zuhörern offenbar besonders am Herzen. Außenpolitisch erstrebe die Hitler-Regierung wie ihre Vorgängerinnen Gleichberechtigung in der Rüstung, ohne die an eine dauerhafte Beruhigung der abendländischen Welt nicht zu denken sei, und auf der Grundlage eines Ausgleichs nationaler Interessen eine „konstruktive“ Neuordnung Europas mit friedlichen Mitteln. Mit Ansprüchen hielt man keineswegs hinter dem Berg. Als „Leitstern unserer Wünsche“, rekapitulierte Abetz, sei die Vereinigung geschlossener deutscher Siedlungsgebiete in einem Staat genannt worden; gemeint waren der Anschluß von Österreich, Danzig und Ostpreußen, die Rückgabe Ostoberschlesiens und des Saargebiets „ohne alle Vorbehalte“ sowie kulturelle Autonomie für deutsche Minoritäten. Kombiniert wurden diese Forderungen mit Bekenntnissen zu Europa - vom ,Dritten Reich' angeblich vor dem Kommunismus gerettet - und gegen den Krieg ${ }^{45}$. Summa summarum keine neue, aber doch eine bemerkenswert offensive, ideologisch einseitige Argumentation, in der, wie Barbara Unteutsch treffend feststellt, gefährliche Verharmlosungen, Geschichtsklitterung und versteckte Drohungen einander ablösten ${ }^{46}$. Den Franzosen sei klargemacht worden, resümierte befriedigt ein deutscher Chronist, daß der Nationalsozialismus „eine deutsche Tatsache" sei, „mit der die Nachbarländer jetzt und zukünftig zu rechnen haben ${ }^{447}$.

Erleichtert registrierte Abetz, daß zumindest Jean Luchaire gewillt schien, auch weiterhin für eine Verbesserung der deutsch-französischen Beziehungen einzutre-

${ }^{44}$ Das sämtliche Teilnehmer aufführende Kommuniqué ist enthalten im Tagungsbericht Luchaires, La jeunesse du IIJe Reich parle, in: Notre Temps, 30. 4. 1933, Sp. 200 f.; die deutsche Fassung in PA/AA, Botschaft Paris 1050/1. Luchaire bemäntelte die Verschiebung des geplanten großen Kongresses mit nicht näher erläuterten materiellen Gründen.

45 Zusammengefaßt nach Luchaire, Notre Temps, 30. 4. 1933, Sp. $202 \mathrm{ff}$., und einer sechsseitigen „Denkschrift des Sohlbergkreises zur Pariser Aussprache vom 21./22. April 1933“, von der Abetz Botschaftsrat Forster am 3. 5. 1933 ein Exemplar übersandte; PA/AA, Botschaft Paris 1050/1. Ihre inhaltlichen Aussagen werden durch Luchaires Bericht weitgehend gestützt.

46 Unteutsch, Sohlbergkreis, S. 272.

47 Ove Hegedüs, Aufbruch - auch in Frankreich, in: DFR 6 (1933), S. 352. 
ten ${ }^{48}$. Im Spätsommer 1932 hatte der Journalist auf wirkmächtige Affinitäten zwischen Nationalsozialismus, typisch deutschen Denkweisen und der Mentalität der jungen Generation jenseits des Rheins hingewiesen. Trotzdem, so mahnte er damals, sei Deutschland ein zu wichtiges und zu eng mit den Geschicken der westlichen Zivilisation verbundenes Land, als daß es den beharrlichen Initiativen für eine Reform des internationalen Systems fremd oder gar feindselig gegenüberstehen dürfte ${ }^{49}$. Nun verschwieg er nicht, daß in den Reihen des von ihm geführten "Comité d'Entente" massive Kritik an den demokratiefeindlichen und antisemitischen Ausschreitungen im Reich laut geworden war. Gleichwohl neige man schon aus informellen Gründen dazu, die bestehenden Verbindungen beizubehalten und das Verständigungswerk, soweit möglich, fortzuführen. Eine intensive Kontaktpflege helfe verhindern, daß zu den vorhandenen Gegensätzen, die freilich nicht unüberbrückbar seien, aufgrund mangelnden Informationsflusses gravierende Mißverständnisse hinzukämen. Das offiziell verbreitete Fazit der Rumpftagung vom 21./22. April fiel denn auch sehr positiv aus: Von einer „atmosphère de cordialité et de sincérité réciproques" war die Rede und davon, daß die deutschen Gäste den innen- und außenpolitischen Kurs ihres Landes ausgiebig erläutert und dabei einiges richtiggestellt (!) hätten ${ }^{50}$. Deutschland, ergänzte Luchaire, befinde sich in einem heftigen Gärungsprozeß, verletze dabei sicherlich des öfteren die Empfindsamkeiten seiner Nachbarn, suche sich jedoch aufrechten Mutes. „Ce courage et cette sincérité sont respectables. "Man müsse dem teutonischen Mahlstrom ohne Feindseligkeit begegnen, die künftige Evolution des Hitler-Staates abwarten und einstweilen den weisen Rat des römischen Kaisers Marc Aurel beherzigen: „Penser ensemble, non. Pousser ensemble, oui." 51

Etlichen Franzosen, die das Geschehen im Nachbarland mit Abscheu verfolgten, war dieser Nenner entschieden zu groß. Ein hitziger Meinungsstreit über Sinn und Legitimation aufgeschlossener Beziehungen zum Nazi-Reich hob an, der gewachsene Freundschaften im radikalsozialistischen Lager entzweite, das stürmische Echo auf die Pariser Tagung reflektiert und Abetz' Anstrengungen, den Sohlbergkreis als unentbehrliches Hilfsinstrument deutscher Frankreichpolitik zu präsentieren, indirekt entgegenkam. Besonders schlagzeilenträchtig beharkten sich zwei alte publizistische Weggefährten der Linken, Albert Dubarry und Victor Basch. Der 63jährige Dubarry, Direktor der Tageszeitung La Volonté, hatte einer von Abetz anberaumten "Sonderbesprechung “ mit Pariser Journalisten und Kulturschaffenden beigewohnt ${ }^{52}$ und die jugendlichen Verständigungsbefürworter beider Länder zu ihrer klarsichtigen Haltung beglückwünscht: „Une influence qui ne peut que contribuer [...] à la pacification des esprits" ${ }^{* 33}$. Basch, 68,

48 Abetz, Das offene Problem, S. 36.

49 Luchaire, Les trois Allemagnes aux prises, in: Notre Temps, 4. 9. 1932, Sp. $611 \mathrm{f}$.

50 Ders., La jeunesse du III ${ }^{\mathrm{e}}$ Reich parle, in: Notre Temps, 30. 4. 1933, Sp. 199ff.; PA/AA, Botschaft Paris 1050/1.

51 Notre Temps, Sp. $205 \mathrm{f}$. Hochzufrieden war Luchaire über deutsche Versicherungen, der Status quo in Elsaß-Lothringen bleibe gemäß Locarno-Vertrag unangetastet.

52 Vgl. „Denkschrift des Sohlbergkreises“; PA/AA, Botschaft Paris 1050/1.

53 Alfred Dubarry, Pour le maintien du contact franco-allemand, in: La Volonté, 4. 5. 1933. Pikanterie am Rande: La Volonté, wo Luchaire bis September 1933 als Generalsekretär 
Philosophieprofessor und Präsident der „Ligue des droits de l'homme“, machte seiner Empörung hierüber in einem geharnischten Brief Luft. Angesichts der eklatanten Verstöße gegen die Menschenrechte in Deutschland hielt er es für schändlichen Verrat an der Demokratie und den Opfern des Nationalsozialismus, bekennende Hitler-Anhänger willkommen zu heißen, die, selbst wenn sie nicht zu den Tätern zählten, zumindest der geistigen Komplizenschaft schuldig seien. Wer versuche, Terror und Unterdrückung zu „erklären“, sie als notwendiges Übel bagatellisiere, befinde sich auf dem besten Weg, sie zu entschuldigen ${ }^{54}$. In einer Replik warf Dubarry seinem Kontrahenten vor, das höchste Gut, den Frieden, auf dem Altar der Demokratie zu opfern. Er verurteilte die gewalttätigen Ausschreitungen im Reich, betrachtete sie indes als vorübergehende Erscheinung und lieferte eine Begründung für den freundschaftlichen Gedankenaustausch zwischen "Comité d'Entente" und Sohlbergkreis, die in den kommenden krisenhaften Jahren noch häufig zur Rechtfertigung zwischenstaatlicher Kontakte herhalten mußte: „Pour servir la paix, les contacts officiels ne suffisent pas [...] des contacts privés sont indispensables. Et si ces contacts ont lieu, il faut qu'y préside un esprit de correction réciproque, de compréhension cordiale. " 55 Abermals antwortete Basch, mit beißendem Spott für den vorgeblichen „Realismus“ namentlich der jüngeren Generation. Er betonte, daß Frieden und Demokratie eine untrennbare Einheit bildeten. Einziges Mittel, den vom Nazi-Regime Verfolgten gerecht zu werden, sei dessen schärfste Mißbilligung; freundliche Empfänge für junge Nationalsozialisten in Paris würden die Barbaren hingegen nur in ihrem verwerflichen Tun ermutigen. Frankreichs Jugend habe die verdammte Pflicht, solches Paktieren zu unterlas$\operatorname{sen}^{56}$.

Auch im engeren Mitarbeiterkreis von Notre Temps bewirkte die Diskussion der künftigen deutsch-französischen Beziehungen eine wachsende Polarisierung. Unmittelbar nach der Pariser Tagung schieden zwei Redakteure aus, weil sie Luchaires Kurs nicht länger mittragen mochten. Bernard Lecache, führender Kopf der "Ligue internationale contre l'antisémitisme“, erklärte ohne Wenn und Aber, $\mathrm{da} ß$ nur Verbindungen zu deutschen Demokraten statthaft seien: „s'entendre avec Hitler, c'est faire le lit, en France, du fascisme et c'est condamner, une deuxième fois, les victimes du Troisième Reich“57. Kaum weniger kategorisch verweigerte der Literat Louis Martin-Chauffier, im Vorjahr beim deutsch-französischen Treffen in Mainz noch als Referent hervorgetreten, jeden weiteren, in seinen Augen

fungierte, erhielt wenigstens bis 1930 Finanzhilfen des Auswärtigen Amtes und veröffentlichte im Gegenzug Artikel über Deutschland und zur Kriegsschuldfrage. Vgl. Bariéty, L'appareil de presse de Joseph Caillaux, S. 388f.

54 Victor Basch, Lettre ouverte à Albert Dubarry, in: La Volonté, 7. Mai.

55 Dubarry, Réponse à Victor Basch, in: La Volonté, 8. Mai.

56 Basch, Paix et démocratie, in: La Volonté, 14. Mai. Die Kontroverse ist unter dem Titel „Français et Hitlériens. A propos d'une rencontre" dokumentiert in Les Cahiers des Droits de l'Homme, 33. Jg. (Nouvelle Série), Nr. 14 vom 20. 5. 1933, S. 319-322. Ein deutscher Beobachter zog aus diesen und anderen Stellungnahmen den Schluß, die programmatischen Erklärungen der sieben Parisfahrer hätten „zweifellos aktivierend auf das junge Frankreich gewirkt “, die an Ostern geführten Gespräche „stärkere Räsonnanz [sic!] gefunden als je zuvor"; Hegedüs, Aufbruch, S. 353.

57 Aus einem Beitrag für Droit de Vivre, zit. in Notre Temps, 21. 5. 1933, Sp. 346. 
unmoralischen Umgang mit Faschisten ${ }^{58}$. 1934 brach die Redaktionsmannschaft vollends auseinander, bezeichnenderweise in direktem Zusammenhang mit Otto Abetz' aufstrebender Karriere unter dem Hakenkreuz. Als der in ernster Bedrängnis geglaubte Karlsruher plötzlich frohgemut als Abgesandter der $\mathrm{HJ}$ durch Paris streifte, um seine Kontakte aufzufrischen und neue zu knüpfen, kehrten auch Pierre Brossolette und Jacques Chabannes, die eine Zusammenarbeit mit autoritär regierten Staaten um des Friedens willen verteidigt hatten, Notre Temps definitiv den Rücken. Sie mißtrauten Abetz ${ }^{59}$ und befürchteten - zu Recht, wie sich zeigen sollte -, daß er verhängnisvollen Einfluß auf den bekanntermaßen käuflichen Jean Luchaire nehmen würde, der nach der Umwandlung seiner Revue zur Tageszeitung und dem politischen Rechtsruck vom 6. Februar einmal mehr in finanziellen Schwierigkeiten steckte. Schon kursierten einschlägige Gerüchte im Pariser Pressemilieu. „Il faut qu'on se tire de là“, entschied Brossolette. „Notre politique de rapprochement, juste et réaliste hier, se retourne maintenant contre son propre idéal. Abetz arrive avec de l'argent à distribuer. Et Jean en a toujours besoin. On ne peut pas continuer." 60 Fortan schrieben sie für linksdemokratische, antifaschistisch ausgerichtete Blätter wie Marianne und L'Europe Nouvelle. Andere verdiente Notre Temps-Mitarbeiter wie Jacques Kayser, Claude Aveline und Jacques Nels wechselten zur neugegründeten, unter anderem von Martin-Chauffier und André Chamson geleiteten Wochenzeitung Vendredi61.

Trotz schneidender Kritik beharrten Jean Luchaire und einige Getreue unterdessen auf dem Standpunkt, daß der Erhalt des Friedens die Fortsetzung und Pflege der Beziehungen zu Deutschland nicht nur rechtfertige, sondern unabhängig vom dort herrschenden politischen System gebiete. Statt Ängste zu schüren und einen unsichtbaren Sperrzaun um die Nachbarn zu errichten, solle man bes-

$58 \mathrm{Vgl}$. seinen Brief an Luchaire, abgedruckt in Notre Temps, 4. 6. 1933, Sp. 439-450.

59 Brossolette wurde in seiner Vorsicht möglicherweise bestärkt durch einen Freund seit Studientagen, Robert Minder. Mit großem zeitlichem Abstand (1977) schilderte der Altmeister der französischen Germanisten seine einzige Zusammenkunft mit Abetz, dem „falschen Europäer", im Januar 1933. Abetz habe um eine Liste christlich inspirierter französischer Romanliteratur gebeten, deren Übersetzung und Verbreitung dazu beitragen sollte, der katastrophal anschwellenden Hitler-Bewegung etwas entgegenzusetzen. Minder schickte eine Liste, erhielt jedoch keine Antwort. Wenig später warnte ihn ein Karlsruher Freund: „Laissez tomber, il s'est vendu aux nazis.“ Minder, Médiateurs alsaciens à Paris, in: Le colloque de Strasbourg 1977, hrsg. von Olbert u. a., S. 107.

60 Mit der Zeitangabe "Frühjahr 1934" überliefert von Chabannes, zit. bei G. Brossolette, Pierre Brossolette, S. 53. Abetz hat stets energisch bestritten, Schmiergelder verteilt zu haben. Belegt ist, daß Luchaire vor dem Krieg über die Deutsche Botschaft Paris monatlich bis zu 3000 Francs für politische Hintergrundinformationen und prodeutsche Berichterstattung erhielt. Außerdem nahm die Botschaft mehrere tausend Exemplare von Notre Temps ab, wie der damalige Presseattaché Eugen Feihl („On pouvait dire à M. Luchaire: „Publiez cet article‘. Alors, il le publiait. “) enthüllte. Zeugenaussage Feihls im Abetz-Prozeß, 18. 7. 1949, pag. 52 f.; AN, 334 AP 49. Vgl. Kap. V der vorliegenden Arbeit.

61 Vgl. Lévy, Autour de Jean Luchaire, S. 127 ff. Wehmütig beschrieb Nels seine allmähliche Entfremdung von Notre Temps: „Le cœur ni l'esprit n'y étaient plus. Les rumeurs qui venaient de l'Allemagne hitlérienne, les rapports toujours cordiaux entre Luchaire et Abetz m'indisposaient et m'inquiétaient [...] Moi aussi, je prenais mes distances. Non sans tristesse." Fragments, S. 123. 
ser klärende Gespräche mit ihnen suchen; das heiße mitnichten „Hitlers Spiel spielen"62. Wiederholt stellte Luchaire die Vorgänge in Deutschland als revolutionären Ausnahmezustand dar, dessen Ende offen und für dessen tiefere Ursachen das könne er, der lange Jahre die wirtschaftliche und seelische Depression und die "geistige Metamorphose“ der jungen Deutschen verfolgt habe, beurteilen - Verständnis angezeigt sei: „la violence d'aujourd'hui est née de la souffrance d'hier"63. In Verbindung mit dem Vorwurf, die Altvorderen hätten diesem Drama tatenlos zugesehen, versuchte er, ein Leitmotiv seines politischen Handelns aufgreifend, den Richtungsstreit der französischen Pazifisten als neue Runde im unvermindert schwelenden Generationenkonflikt zu interpretieren ${ }^{64}$. Der Aufstieg des Nationalsozialismus war in seinen Augen kein Grund, die Perspektive zu ändern. Seine Überzeugungen, sein ,pacifisme à tout prix' blieben unerschüttert, ebenso sein Glauben an die segensreiche Funktion lebendiger zwischenstaatlicher Kontakte, ohne die jedes Gespräch auf Regierungsebene gleichsam im luftleeren Raum stattfinde ${ }^{65}$. Eine gewisse Trotzhaltung und das einträgliche Werben der Deutschen um seine Dienste gesellten sich, der inneren Distanz nicht eben förderlich, hinzu. Bei all dem galt Luchaire, ähnlich wie Abetz, ein deutsch-französisches Miteinander als kategorischer Imperativ, an welchem er, scheinbar unberührt von ideologischen Barrieren, moralischen Fragezeichen und dem fortschreitenden Verlust französischer Machtpositionen, meinte festhalten zu müssen ${ }^{66}$. Den letztlich schrankenlosen Eroberungswillen der nationalsozialistischen Führung, der eine für Frankreich akzeptable Partnerschaft ausschloß, haben beide, wie zu zeigen sein wird, gründlich unterschätzt, teilweise fahrlässig ignoriert, meist nur vermeintlich konterkariert, unter dem Strich sogar gefördert. Vor 1933 und auch danach war Luchaires Engagement mit der Vision eines geeinten Europas verknüpft, jenes von Abetz mit dem Ziel einer Revision der in Versailles gezogenen Grenzen. Diese „Geradlinigkeit“, in Kombination mit bestimmten Charakterzügen, erwies

$62 \mathrm{Vgl}$. Luchaire, Réactions aux réunions franco-allemandes, in: Notre Temps, 7. 5. 1933, Sp. 247-250.

63 Ders., Retour à la querelle des générations, in: Notre Temps, 14. Mai, Sp. 295-300; mit gleichem Tenor Jean-Louis Crémieux, La jeunesse allemande, Notre Temps, 28. Mai, Sp. 391-395. Mit deplazierter Jovialität appellierte Guy Crouzet an die Einsicht der Franzosen, daß Volkscharaktere völlig unterschiedlich beschaffen seien und die Deutschen, so es ihnen gefalle, das Recht hätten, sich an Massenaufmärschen, Gleichschritt, Bier und völkischer Gefühlsduselei zu ergötzen. Crouzet, L'esprit de la paix à l'épreuve, Notre Temps, 30. April, Sp. $217 \mathrm{ff}$.

64 Luchaire, Retour à la querelle des générations, sicherlich auch ein Konter gegen die gallige Koketterie Baschs mit seinem Alter, das ihm vermutlich den rechten Durchblick verstelle. Siehe ferner die Sonderausgabe von Notre Temps vom 2./9. 7. 1933, „Querelle des générations et crise des démocraties".

65 Luchaire, La paix, problème de conscience?, in: Notre Temps, 25. 6. 1933, Sp. 565. Damit bezog er unmißverständlich Position gegen Basch, der verlangt hatte, sich auf die nötigsten offiziellen Beziehungen zu Deutschland zu beschränken (La Volonté, 7. Mai). In den kommenden Jahren zeigten sich weite Bevölkerungskreise, allen voran die französischen Kriegsveteranen, gesprächsbereit, eine entscheidende Voraussetzung für den Erfolg der NS-Propaganda insgesamt und für Abetz' Initiativen im besonderen.

66 Vgl. Bertrand de Jouvenels selbstironischen Kommentar in La République vom 7. 5. 1933: „Je veux un rapprochement. Là est mon crime!“ 
sich als verhängnisvoll. Mit beklagenswerter Konsequenz entwickelte sich der eloquente, über die Maßen geschäftstüchtige Franzose zum allzeit verfügbaren Claqueur der immer aggressiver sich gebärdenden NS-Diplomatie, sein ebenso sendungsbewußter wie obrigkeitsbeflissener deutscher Freund zu einem ihrer umstrittensten Handlanger. In welche Untiefen sie ihre schleichende Verstrickung führen würde, ließ sich im Frühjahr 1933 kaum absehen; die Gabelung, an der sie auf „faschistische Abwege ${ }^{\text {"67 }}$ gerieten, war allerdings erreicht.

Aus Paris heimgekehrt, war Abetz Verdächtigungen und Ermittlungen der politischen Polizei ausgesetzt, blieb aber von weiterer Unbill verschont. Er formulierte umgehend eine für die Reichsbehörden bestimmte Denkschrift, die die Tagung als durchschlagenden Erfolg wertete und seine Aktivitäten einmal mehr als vorzügliches Mittel anpries, zum Nutzen der neuen Regierung auf die beunruhigte französische Öffentlichkeit einzuwirken. Den nach längerem Tauziehen mit dem Auswärtigen Amt gewählten Veranstaltungsrahmen begründete er nun, Einsichtsfähigkeit demonstrierend, damit, daß „die Entstellung der innerpolitischen Entwicklung Deutschlands im Ausland einer fruchtbaren außenpolitischen Aussprache größeren Stils zum vorgesehenen Zeitpunkt im Wege zu stehen schien“. Anderseits, verteidigte er seine Hartnäckigkeit, habe es die „auch in Frankreich um sich greifende antideutsche Greuelpropaganda“ erfordert, „im Sinne der Aufforderung des Herrn Reichskanzlers alle Beziehungen zu ihrer Bekämpfung auszunützen". Die "Gefahr eines Umfalls der vom Sohlbergkreis in die Antiversaillesfront gewonnenen französischen Verbände" sei ,immer akuter" geworden. Mit sicherem Gespür für zugkräftige Argumente berief er sich kurzerhand auf Hitler, und das Ergebnis, das er präsentierte, sollte alle Zweifler Lügen strafen: „Schon unser Kommen allein und die Erneuerung alter persönlicher Bindungen war für die jungen Franzosen Ursache genug, Versteifung und Ablehnung aufzugeben, und die Atmosphäre des guten Willens war geschaffen." Man habe über die politischen, kulturellen und gesellschaftlichen Ursachen und Ziele der "nationalen Revolution" informiert und für ihr Verständnis unerläßliche Zusammenhänge aufgedeckt: „Die Franzosen wußten nicht, daß die Mehrheit der deutschen Jugend das System 1918 bis 1933 nur als innerpolitisches Exekutionsinstrument der Siegermächte [...] empfunden hat. So erklärt sich auch die in Frankreich so schwer verständliche Behandlung der Juden, die sich mit dem System identifiziert und daher am stärksten in seinen Fall verstrickt hatten." Die Aufgeschlossenheit seiner Pariser Gesprächspartner nannte Abetz "frappierend"; am Ende hätten sich etliche „begeistert zur geistigen Parole der deutschen Revolution“ bekannt, „und diejenigen, welche uns nicht zu folgen vermochten, riefen zu sachlichem, gutnachbarlichem Verstehenwollen unseres politischen Weges auf", womit zumindest ein neutralisierender Effekt bewirkt sei. Gestützt auf diese Erfolgsbilanz, tat Abetz dann gerade so, als sei eine ungehinderte und vor allem selbständige Fortsetzung seiner Aktivitäten bereits ausgemachte Sache: „Es wird Aufgabe aller weiteren Sohlbergarbeit sein, diese Ebene der Betrachtung zu wahren, weil erst von ihr aus die Mißverständnisse, welche sich im Ausland um die taktischen Maßnahmen [!]

67 Ein Ausdruck des Genfer Historikers Philippe Burrin; vgl. ders., La dérive fasciste. 
der deutschen Revolution häufen, zu beheben sind. Die Mehrzahl der durch die Pariser Besprechungen erfaßten Zeitungen und Zeitschriften wird von uns laufend mit Artikeln beliefert werden [...] Auch die persönlichen Kontakte werden systematisch durch Besuche, Briefwechsel und Vorträge ausgebaut."68

Kann es einen zwingenderen Beweis dafür geben, daß sich Abetz, sein Fähnchen karrierebewußt nach dem Wind drehend, zur willfährigen Anpassung an die neuen Machthaber und offensiven Verbreitung ihrer Propaganda bereit fand?69 Binnen weniger Wochen, so scheint es, war aus dem aufmüpfigen bündischen $\mathrm{Au}$ tonomisten ein linientreuer, zuverlässiger Gefolgsmann Hitlers geworden, der seine vielfältigen Verbindungen nach Frankreich und sein frankophiles Renommee nicht mehr allein dazu benützte, traditionellen deutschen Revisionsansprüchen Geltung zu verleihen, sondern darüber hinaus für eine wohlwollende Tolerierung der NS-Diktatur warb und ihren Terror gegen Oppositionelle und zum Feindbild verdammte Bevölkerungsgruppen zu legitimieren suchte. Die „Metamorphose vom jugendbewegten Idealisten zum nationalsozialistischen Funktionär" 70 hatte ein entscheidendes Stadium erreicht. Über mögliche Motive seines auf den ersten Blick prinzipienlosen Verhaltens, das massive Zweifel an seiner politischen wie charakterlichen Lauterkeit weckt, wird gleich zu sprechen sein. Zunächst ist festzuhalten, daß Abetz' demonstrative Kooperationsbereitschaft bei Behörden und in Parteikreisen zusehends auf Resonanz stieß. Nach einigen Monaten der Ungewißheit, wohl auch persönlicher Zurückhaltung im Gefolge kleinerer Scharmützel mit der Geheimpolizei wurde er vom Herbst 1933 an nicht nur geduldet, sondern im Kontext der an Kontur gewinnenden, auf Beschwichtigung zielenden deutschen Frankreichpolitik regelrecht umworben. Die Reichsjugendführung (RJF), soeben dabei, ein eigenes Grenz- und Auslandsamt einzurichten, begann sich für seine Mittlerfähigkeiten zu interessieren, und mit finanzieller Unterstützung des Auswärtigen Amtes durfte er unter dem Signum des Sohlbergkreises, also im Zeichen äußerer Kontinuität, eine weitere deutsch-französische Zusammenkunft organisieren. In Berlin habe sich allmählich „eine objektivere und gerechtere Würdigung der Arbeit des Sohlbergkreises" durchgesetzt, kommentierte er diese Entwicklung, die seinen hauptberuflichen Einstieg in die halbamtliche nationalsozialistische Außenpolitik brachte, noch in seinen Memoiren mit spürbarer Genugtuung ${ }^{71}$.

Zur Vorbereitung des für Januar 1934 geplanten Treffens, das namhafte französische Jugendfunktionäre, Publizisten und Schriftsteller in die Reichshauptstadt lockte, weilte Abetz Ende Oktober 1933 in Paris. Dort stieß er auf „nicht unerhebliche" Schwierigkeiten, "da die Gegner unserer Arbeit vor den häßlichsten Verunglimpfungen unserer französischen Partner nicht Halt machen“. Luchaire

68 „Denkschrift des Sohlbergkreises zur Pariser Aussprache vom 21./22. April 1933“; PA/ AA, Botschaft Paris 1050/1.

69 Mit diesem Tenor Tiemann, Jugendbeziehungen, S. 135 f., 249; Thalmann, Du cercle de Sohlberg au Comité France-Allemagne, bes. S. $71 \mathrm{ff}$. Differenzierter Unteutsch, Sohlbergkreis, S. $85 \mathrm{f}$.

70 Tiemann, S. 251.

71 Abetz, Das offene Problem, S. 39. 
war nach der Ostertagung und seinem "mutigen Eintreten für Deutschland in Presse und Versammlungen" derart attackiert worden, daß ein Wechsel an der Spitze des „Comité d'Entente " vorteilhaft erschien ${ }^{72}$. Den Vorsitz hatte nun Bertrand de Jouvenel, ebenfalls ein ausgewiesener Befürworter des Dialogs mit HitlerDeutschland ${ }^{73}$, für den er auch rechte Gruppierungen wie die "Jeunesses patriotes" und die „Action Française“ zu interessieren suchte ${ }^{74}$. Trotz erschwerter Bedingungen sei das Comité entschlossen, den „Gedanken eines freundschaftlichen Ausgleichs der nationalen Interessen " zu verteidigen, meldete Abetz, der im übrigen gezielt an Skeptiker und NS-Gegner herantrat, "um aufgrund der persönlichen Beziehungen politisch aufklärend wirken zu können", offenbar mit dem $\mathrm{Er}$ folg, daß etliche Verbände ihren ablehnenden Standpunkt überdenken und wenigstens Beobachter nach Deutschland entsenden wollten, darunter solche, die das Comité zwischenzeitlich schon verlassen hatten. Die Berliner Veranstalter, resümierte Abetz, dürften „auf eine sehr repräsentative Beschickung aus Frankreich rechnen"75. Das war angesichts früherer Teilnehmerkreise übertrieben; die tiefere Bedeutung der Sondierungen lag sicherlich darin, daß es gelang, einige bewährte Kontakte über die Wechselfälle des Jahres 1933 hinwegzuretten. Die etwa 15köpfige Abordnung, die Anfang Januar nach Deutschland fuhr, rekrutierte sich im Kern aus vertrauten Gesichtern und Organisationen, vorneweg Bertrand de Jouvenel vom "Comité d'Entente". Notre Temps entsandte Léon-Marie Brest und den Sohlbergveteranen Alfred Silbert, der zwischenzeitlich in Indochina gearbeitet hatte, die künftigen Friedensaussichten pessimistisch beurteilte, indes wie so viele Landsleute überzeugt war, "qu'il faut toujours essayer ${ }^{\alpha 76}$. Auch das „Groupement universitaire pour la Société des Nations" und die "Ligue d'action universitaire républicaine et socialiste“ (Weil-Curiel) waren erneut vertreten, ebenso Drieu La Rochelle, der ein freundschaftliches Verhältnis („une espèce d'amitié") zu Abetz entwickelte ${ }^{77}$.

So effektiv sich Abetz wieder einmal in Szene zu setzen wußte, zumindest für die französische Diplomatie war er noch immer ein Niemand, was besonders in

72 Abetz an Auswärtiges Amt, 31. 10. 1933, mit dreiseitigem „Bericht Pariser Reise Abetz 22.-28. Oktober 1933“; PA/AA, Botschaft Paris 1050/1. Der Briefkopf des Anschreibens weist Abetz als Geschäftsführer, Friedrich Bran als Leiter des Sohlbergkreises aus, was Brans Angaben über einen taktischen Führungswechsel im Frühjahr 1933 (siehe Anm. 26) stützt. Abetz' Bericht zufolge erhielt er für seine Sondierungen vom Auswärtigen Amt 450 RM.

73 Vgl. de Jouvenel, Mort de l'Allemagne démocratique, in: DFR 6 (1933), S. 218-220.

74 Thalmann, Du cercle de Sohlberg au Comité France-Allemagne, S. 74, mutmaßt, das AA könnte Luchaires Ablösung unter Hinweis auf gesellschaftliches Prestige und politischen Einfluß der Familie de Jouvenel betrieben haben. Abetz nennt als zusätzlichen Rücktrittsgrund die starke berufliche Inanspruchnahme des Freundes nach der soeben erfolgten Umwandlung von Notre Temps in eine Tageszeitung.

75 „Bericht Pariser Reise Abetz“; PA/AA, Botschaft Paris 1050/1. Mit gleichem Tenor Abetz an Legationsrat Kühn (Paris), 18.11. 1933, ebenda. In diesem im Original vorliegenden Dokument hat Abetz das Wort "Leiter" (des Sohlbergkreises) handschriftlich in „Geschäftsführer“ verbessert.

76 Zeugenaussage Silberts im Abetz-Prozeß, 19.7. 1949, pag. 55 f.; AN, 334 AP 49.

77 Vgl. Drieu La Rochelle, Fragment de mémoires 1940-1941 (niedergeschrieben im Jahre 1943), S. 37. 
Anbetracht der jüngsten, öffentlich ausgefochtenen Kontroversen um Sinn und Zulässigkeit von Austauschbeziehungen mit dem ,Dritten Reich' doch etwas erstaunt. Auf eine Anfrage des Quai d'Orsay, von de Jouvenel über das neue Vorhaben informiert, antwortete Botschafter François-Poncet, er werde sich beim Karlsruher Konsulat hinsichtlich der Seriosität des Sohlbergkreises erkundigen, desgleichen über den Leumund von Abetz, den er fälschlich als Fabrikdirektor („directeur d'usine“) einstufte. Ob es opportun war, der Einladung nach Berlin zu folgen, hing für François-Poncet vom jeweils letzten Stand im deutsch-französischen Verhältnis ab; sollten Konflikte ausbleiben, spreche nichts gegen das Treffen ${ }^{78}$.

Berlin als Tagungsort war gewählt worden, um den Gästen „einen unmittelbaren Eindruck unserer nationalsozialistischen Politik zu geben“, wie Friedrich Bran in Hochschule und Ausland vermerkte ${ }^{79}$. Diesem Zweck diente ein „Feuerwerk gezielt-propagandistischer Darbietungen" 80 , ein Dinner mit hochrangigen HJ-Funktionären ebenso wie der Besuch eines Arbeitslagers und eines Spielscharabends der Hitlerjugend 81 . Die deutschen Referenten, unter ihnen der Präsident der Reichsschrifttumskammer, Hans Friedrich Blunck, kehrten die vermeintlichen Segnungen des Nationalsozialismus für Staat, Wirtschaft und Kultur mit einer Mischung aus Heilsgewißheit, Überlegenheitsdünkel und Anspruchsdenken heraus, die den ohnehin verblaßten Traum einer jugendlichen Internationale als Gegenpol und Korrektiv zur politischen Wirklichkeit vollends zum Trugbild verzerrte. Walther Reusch von der Deutschen Studentenschaft geißelte Frankreichs „Hauptfehler" - die Illusionen bezüglich der Anwendbarkeit des Versailler Diktats -, ein Berliner HJ-Führer schwadronierte über jüdische Störenfriede im Land und die Verdienste der Partei um die Reinhaltung der deutschen Rasse ${ }^{82}$. Zugleich aber waren die NS-Offiziellen bemüht, sich als berechenbare Partner zu präsentieren, wozu sie sich in bezeichnender Weise des Sohlberg-Mythos bedienten. „Die Vertreter der Hitlerjugend stehen heute vor Ihnen als Repräsentanten der gesamten deutschen Jugend [...] Auch hier im Sohlbergkreis steht Ihnen diese Jugend gegenüber“, sagte Nabersberg in seiner Begrüßungsrede. „Helfen Sie uns beim Brückenbau. "83 In einer amtlichen Pressemitteilung hieß es, die „Tradition

78 François-Poncet an das französische Außenministerium, 4. 12. 1933; Archives diplomatiques du MAE/Nantes, Berlin: Série B, Télégrammes de Berlin, Carton 128. Für diesen Hinweis danke ich Corinna Franz (Univ. Bonn).

79 Bran, 5. Deutsch-französische Jugendbegegnung des Sohlbergkreises, in: Hochschule und Ausland 12 (Februar 1934), S. 41-46, das Zitat auf S. 43. Als weitere Quellen wurden herangezogen: DFM, Januar-Februar 1935, S. $122 \mathrm{f}$. ("Jahresrückschau 1934"); die Notre Temps-Ausgaben vom 5.-10. 1. 1934; die gründlichen Analysen von Tiemann, Jugendbeziehungen, S. $251 \mathrm{ff}$., und Unteutsch, Sohlbergkreis, S. $86 \mathrm{ff}$.

80 Tiemann, S. 254.

81 Silbert berichtet, er und Drieu La Rochelle seien auch von Alfred Rosenberg empfangen worden, wobei Abetz dolmetschte; wie Anm. 76.

82 Peinlich vor diesem Hintergrund Abetz' spätere Behauptung, die Gastgeber seien den „Volljuden" in der französischen Delegation ausgesucht höflich begegnet. „Curriculum vitae", pag. 6; AN, F 7/15331. Das offene Problem, S. 39.

83 DNB, Nr. 19 vom 4. 1. 1934, „Deutsche und französische Jugend auf der Tagung des Solberg-Kreises“" [sic!]; PA/AA, R 70545. 
des Sohlbergkreises“ ermögliche „eine offene, kameradschaftliche Diskussion“ zwischen jungen Franzosen und Nationalsozialisten ${ }^{84}$, und zum Abschluß der Tagung meldete das Deutsche Nachrichtenbüro: „Der Sohlbergkreis wird getreu seiner Überlieferung und seines Auftrags von der Reichsjugendführung die Beziehungen der Jugend beider Nationen auch weiterhin pflegen." 85 Gleichschaltung und Vereinnahmung der Karlsruher Verständigungsinitiative waren offenkundig vollzogen. Bran seinerseits stellte die Berliner Veranstaltung als konsequente, auf Kontinuität bedachte Fortsetzung der 1930 begonnenen Arbeit dar, die in Frankreich „für unseren Volkstumsbegriff“ und „für unsere nationalsozialistische Revolution "Verständnis geweckt sowie "drüben den Revisionsgedanken gefördert" habe. Nachdem „eine Epoche unheilvoller deutscher Zwietracht" abgeschlossen worden sei, könne „das Verhältnis der erbfeindlichen Nachbarn eine neue Grundlage erhalten" 86 . Die Gäste, streckenweise beeindruckt von der geballten Demonstration kraftstrotzender Selbstsicherheit, beließen es bei eher zaghaften Einwänden und waren nicht einmal einer Meinung, ob drohende Konflikte besser im Rahmen des Völkerbundes oder in bilateralen Verhandlungen zu entschärfen seien. Drieu La Rochelle meinte, die Franzosen hätten weder die verheerenden moralischen Auswirkungen der Reparationszwänge noch die in der Krise zu suchenden Antriebskräfte der deutschen Massenbewegung jemals hinreichend erkannt, noch seien sie in vergleichbarem Maße marxistischen Parolen ausgesetzt gewesen (womit er sich offenbar den aggressiven Antisemitismus des HitlerRegimes erklärte). Er forderte Verständnis für den „deutschen Sozialismus“ und interpretierte das nationalsozialistische Gesellschaftskonzept als notwendige „Blutsauffrischung der Führerschicht“, ohne daß Deutschland deswegen auf ein Monopol des Germanentums in der Welt pochen dürfe. Das „nordische Element im Franzosentum" sah Drieu als künftigen Brückenkopf zwischen beiden Nationen, ebenso die Gilde der Schriftsteller, deren Aufgabe laute, „die deutsche Art in Frankreich verständlich zu machen".

Die französischen Gäste reisten mit gemischten, aber keineswegs feindseligen Gefühlen nach Hause. Gesandtschaftsrat Kühn, der in den nächsten Wochen mehrfach Presseausschnitte über öffentliche Äußerungen der Berlinfahrer übermittelte, resümierte, vor allem de Jouvenel und Weil-Curiel machten „keinen Hehl" aus ihren günstigen Eindrücken ${ }^{87}$. Kritischer, vielleicht am treffendsten beschrieb René Georges-Etienne, wie Weil-Curiel ein Delegierter der „Ligue d'action universitaire républicaine et socialiste“, die Stimmungslage: „Notre impression générale est qu'il est évidemment impossible, pour nous Français, de nous entendre sur le terrain idéologique avec les jeunes Allemands, qu'il est également très difficile de s'accorder sur les problèmes politiques, mais qu'en matière économique, le mouvement national-socialiste mérite d'être mieux compris et mieux étudié." ${ }^{88}$ Ökonomische Aspekte fesselten wie üblich auch de Jouvenel, der schon in

84 Ebenda.

85 DNB, Nr. 43 vom 7.1. 1934, ebenda.

86 Bran, Jugendbegegnung, S. $41 \mathrm{f}$.

87 Kühn (Paris) an Auswärtiges Amt, 27. 1. 1934; PA/AA, Botschaft Paris 1050/1.

88 Zit. nach den Cahiers des Droits de l'Homme, in: Kühn an AA, 16. 2. 1934, ebenda. Bran 
Berlin „großes Verständnis für Deutschlands Bemühungen um die Neuordnung des eigenen Wirtschaftsraumes" bekundet hatte ${ }^{89}$. Silbert für seinen Teil honorierte die "sympathische Glut" der Hitlerjungen, denen er begegnet war: „leur enthusiasme était réel" 90 . Drieu La Rochelle sah seine faschistischen Neigungen bestärkt, was sich umgehend im schriftstellerischen Werk niederschlug91. Abetz berichtete über „sehr begeisterte Briefe“ aus Frankreich, die zeigten, daß die Partner ihre Impressionen "mit Eifer weitertragen "92. Insgesamt darf man der Tagung einen Werbeeffekt für das ,Dritte Reich' bescheinigen. Entscheidend aus Abetz' Sicht mußte sein, daß sich das vom Sohlbergkreis geknüpfte Beziehungsnetz wiederum als tragfähig erwiesen hatte, obwohl die Maschen dünner waren als zu Beginn der dreißiger Jahre. Doch auf dem Erreichten ließ sich aufbauen, in Frankreich wie in Deutschland, und Abetz frohlockte: „Jedenfalls ist unsere Arbeit jetzt über den kritischen Punkt hinweg, und wir haben für 1934 neue Möglichkeiten vor uns. " ${ }^{93}$ Sogleich schmiedete er Pläne: Französische Jugendliche sollten Ostern und die Sommerferien im Schwarzwald verbringen; die nächste Tagung von Sohlbergkreis und "Comité d'Entente" war für August vorgesehen, eventuell auf einem Landgut der Jouvenels nahe Orléans. Schirach oder Carl Nabersberg, Leiter der RJF-Auslandsabteilung, sollte auf Einladung französischer Verbände im Rahmen einer großen Jugendkundgebung in Paris sprechen, ein Projekt, an dem besonders ein politisch heterogener Kreis um den Schriftsteller Jules Romains Interesse zeigte ${ }^{94}$. Außerdem regte Abetz einen Artikeldienst für deutsch-französische

war nach dem Krieg Mitglied in einem Freundeskreis der „Ligue d'action“, dem GeorgesEtienne präsidierte. Das geht aus einem Bericht über die Generalversammlung des Kreises am 25. Oktober 1978 hervor; Privatbesitz Bran (Kopie beim Verf.). In einem Rückblick auf die Verbandsgeschichte bekannte der frühere Vorsitzende der Sektion Paris, Roger Pinto: „A la L.A.U.R.S. nous étions européens, et donc partisans du rapprochement franco-allemand. Mais pas à n'importe quelles conditions."

89 Zit. nach Bran, Jugendbegegnung, S. 44.

90 Wie Anm. 76.

91 In einem Beitrag für die Nouvelle Revue Française schrieb er: „Or moi, je suis séduit par le courage des fascistes [...] et comme ils sont seuls entièrement courageux en Europe, je veux espérer encore qu'ils emploierent ce courage à faire le socialisme. Car si les fascistes ne font pas le socialisme, qui le fera?" Drieu La Rochelle, Une semaine à Berlin, in: NRF, Februar 1934, S. 887. Zu diesem Berlinaufenthalt und den hierbei gewonnenen Eindrükken, die auch die Endfassung des im November 1934 veröffentlichten Buches Socialisme fasciste beeinflußten, siehe Andreu/Grover, Drieu La Rochelle, S. 264 ff.; eine zeitgenössische Charakterisierung Drieus durch de Jouvenel, abgedruckt in ders., Voyageur, S. 201; Hofer, Faschistoide Literatur, in: Kohut (Hrsg.), Literatur der Résistance und Kollaboration, I, S. $119 \mathrm{ff}$.

92 Abetz an Konsul Depfel (AA), 30.1. 1934, erstmals mit „Heil Hitler“ unterzeichnend; PA/AA, Botschaft Paris 1050/1.

93 Ebenda.

94 Ebenda und Notiz Epting (DAAD-Paris) über eine Besprechung mit Abetz, 3. 4. 1934. Der Pariser Botschaftsattaché v. Dincklage notierte hierzu am 12. April, Romains habe einflußreiche Persönlichkeiten von den Neosozialisten bis zu den Croix de feu um sich geschart, so daß Schirachs Emissär „nicht vor einem x-beliebigen oder unmaßgeblichen Milieu, sondern vor einer Versammlung sprechen [würde], von welcher die Rede wieder in weiteste Schichten ausstrahlen würde“; ebenda. Zu Romains' "Gruppe des 9. Juli“" siehe Burrin, La dérive fasciste, S. 82 f.; Andreu, Révoltes de l'esprit, S. 107-111. Mehrere Quel- 
Themen an, schließlich habe man „Zugang zu etwa 20 Zeitschriften“ des Nachbarlandes. Bedauerlich fand er, "daß alle diese Initiativen nicht mit dem nötigen Maße an Zeit und Geld verfolgt werden können. So muß manches unerledigt bleiben, das für das Deutschlandurteil der jungen Franzosen nützlich sein könnte." $" 95$

\section{Anpassung mit Hintergedanken: Abetz' Weg in die HJ}

Dies sollte sich grundlegend ändern, denn schon bald standen ihm Ressourcen in ungekannter Größenordnung zur Verfügung. Sein Konzept, sich zugleich als Wegbereiter eines friedlichen Ausgleichs und loyaler Interpret der Regierung Hitler zu profilieren, ging auf und ermöglichte ihm den Einstieg in eine steile Karriere unter dem Hakenkreuz. Auf Vorschlag von Nabersberg, der die Berliner Veranstaltung positiv bewertete, und Friedhelm Kemper, der verschiedene Aussprachen mit der $\mathrm{HJ}$ vermittelt hatte, offerierte ihm die Reichsjugendführung vermutlich noch im Januar 1934 ihr Frankreichreferat. Vorgabe: die Intensivierung der deutsch-französischen Jugendbeziehungen ${ }^{96}$. Auch die Kulturabteilung des Auswärtigen Amtes soll ihn für diese Funktion empfohlen haben"7. Abetz indessen zögerte und stellte „Bedingungen“, um sich gestalterische Freiheiten zu bewahren. Seine Behauptung, der Sohlbergkreis sei daraufhin „als unabhängige Organisation" in die Reichsjugend integriert worden ${ }^{98}$, suggeriert durchschlagenden Verhandlungserfolg, spiegelt freilich nicht die Wirklichkeit, sondern allenfalls persönliches Wunschdenken. Das subjektive Gefühl, weitgehend selbständig zu operieren, wurde durch sein rasches Hineinwachsen in eine Schlüsselposition der halbamtlichen deutschen Frankreichpolitik, von Hitler gefördert und in gewollter Abgrenzung zur offiziellen Diplomatie betrieben, fraglos genährt.

len weisen darauf hin, daß ein Vortrag Nabersbergs in Paris tatsächlich zustande kam. In der "Jahresrückschau 1934“ der DFM wird als Datum der 16. Juni, als Thema „das Wollen der deutschen Jugend “ genannt (Januar-Februar 1935, S. 122). Schirach erwähnt den Auftritt seines Abteilungsleiters (Hitler-Jugend, S. 154) und zählt ihn zu den seither „wesentlichsten Begegnungen zwischen deutscher und fremder Jugend“. Johannes Maaß (Deutsche Studentenschaft) schreibt in einem Bericht vom Juli 1934, daß er während seines jüngsten Parisaufenthalts Nabersberg "bei seinem Vortrag an die Hand“ gegangen sei; enthalten in: Böhme (AA) an Botschaft Paris, 20.7. 1934, ebenda. Über den Inhalt von Nabersbergs Ausführungen konnte nichts ermittelt werden. Nabersberg, Jg. 1908, war in der Folge Abetz' direkter Vorgesetzter und nachweislich wiederholt an organisatorischen Besprechungen mit Franzosen beteiligt. Romains referierte am 12. November 1934 auf Einladung des Sohlbergkreises in Berlin.

95 Abetz an Depfel, 30. 1. 1934; PA/AA, Botschaft Paris 1050/1.

96 V.gl. „Vernehmungsniederschrift" vom 7.12. 1937, pag. 1f.; BDC/Abetz. Vernehmung durch John Fried am 28. 5. 1947, pag. 1; StA Nürnberg, KV-Anklage, Interrogations, A 2. Affidavit Kemper, Scheinwerfer, Nr. 19 (September 1949).

97 Abetz-Prozeß, 12. 7. 1949, pag. 14; AN, 334 AP 49. Das offene Problem, S. 39.

98 Verhörprotokoll Nr. 204/4 der Renseignements Généraux vom 21. 11. 1945, „Circonstances de l'adhésion d'Otto Abetz au National-Socialisme“; AN, F 7/15331. Vgl. Abetz, Das offene Problem, S. 40: „Meinen Bedingungen wurde entsprochen“. 
Gesichert erscheint, daß er darauf bestand, ehrenamtlich tätig zu werden, und dadurch privat in einen erheblichen finanziellen Engpaß geriet. Sein Antrag auf Beurlaubung aus dem badischen Schuldienst für zunächst zwei Jahre und Versetzung an ein Berliner Gymnasium wurde zwar bewilligt. Doch nachdem er mit seiner Familie nach Berlin gezogen und zum 31. Juli 1934 im Rang eines Unterbannführers der Hitlerjugend beigetreten war, nahmen ihn RJF und bald auch Ribbentrop, seine vielen Reisen und nicht zuletzt die eigenen Ambitionen derart in Anspruch, daß er keine Unterrichtstätigkeit mehr ausübte ${ }^{99}$. Jules Romains, der die Eheleute Abetz im November in ihrer bescheidenen Etagenwohnung besuchte, fühlte sich an ein Studentenpärchen auf dem Montparnasse erinnert, das von Luft und Liebe lebt. Suzanne erzählte ihm, die schwindenden Reserven hätten eine Anleihe bei ihrer Familie in Lille notwendig gemacht. Otto stelle lediglich Reisekosten in Rechnung, weigere sich aber, Gehalt zu empfangen, weil seine Arbeit dadurch kompromittiert werden könnte ${ }^{100}$. Wie lange dieser Zustand andauerte, läßt sich nicht exakt rekonstruieren. Nach dem Krieg erklärte Abetz einmal, das ganze Jahr 1935 ohne geregelte Einkünfte geblieben zu sein ${ }^{101}$. An anderer Stelle gab er an, von 1935 bis 1939 in Höhe seiner letzten Assessorenbezüge entschädigt worden zu sein ${ }^{102}$. Spätestens von 1936 an vergütete ihm die Dienststelle Ribbentrop nachweislich $850 \mathrm{RM}$ brutto im Monat ${ }^{103}$. Daß er so perfide war, eine Existenz nahe der Armutsgrenze vorzutäuschen, um französisches Mißtrauen zu zerstreuen, glaubten nicht einmal spätere Gegner; etliche von ihnen hatten $1934 \mathrm{im}$ Gegenteil den bestimmten Eindruck, mit einem um Anständigkeit bemühten, insgeheim sogar gegen seine Regierung opponierenden Mann zu verkehren. $\mathrm{Da} ß$ er sich anderseits auf Finten verstand und schon geraume Zeit als kämpferischer Anhänger des Nationalsozialismus gerierte, rückt erneut die Frage nach seinen Motiven und Absichten in den Brennpunkt.

$\mathrm{Zu}$ Beginn und nach dem Zusammenbruch des ,Dritten Reiches' versuchte Abetz den Franzosen sein engagiert-linientreues Gebaren als eine Art Doppelspiel zu erklären, als verantwortungsbewußt kalkulierten Kunstgriff im Interesse einer höheren Sache. Allen Anwürfen zum Trotz beteuerte er, sich mit den Nationalsozialisten nicht identifiziert, sondern lediglich arrangiert zu haben, um bedenklichen Entwicklungen nach Kräften steuern zu können: „Die Verständigungsarbeit mit Frankreich war unter Hitler unendlich viel schwieriger, aber da-

99 Vgl. Lebenslauf vom 23. 8. 1937 und Angaben zur Person vom 13. 2. 1944; BDC/Abetz. Ferner „Curriculum vitae" vom November 1945, pag. 7; AN, F 7/15331. Abetz-Prozeß, 12. 7. 1949, pag. 15; AN, 334 AP 49.

100 Vgl. Romains, The Nazi Mystery, in: The Saturday Evening Post, 9.11. 1940, S. 70; in wortgetreuer Entsprechung ders., Sept mystères, S. 237f. Von Suzanne Abetz bestätigt bei einer Vernehmung im Oktober 1945; AN, F 7/15331, Protokoll Nr. 204/45bis. Lazareff berichtet ebenfalls von Bitten Suzannes um materielle Unterstützung, im besonderen Kinderkleidung. Er schließt daraus, Abetz sei wohl nicht zuletzt aus finanziellen Gründen zu Ribbentrop gewechselt, zumal 1935 ein zweites Kind unterwegs war; Dernière édition, S. 266. Abetz nannte seine Tätigkeit für die RJF „nebenamtlich“; Vernehmungsniederschrift vom 7. 12. 1937, pag. 1; BDC/Abetz.

101 „Curriculum vitae“, pag. 7; AN, F 7/15331.

102 Vernehmung durch John Fried, pag. 2; StA Nürnberg, KV-Anklage, Interrogations, A 2.

103 Belegt bei Jacobsen, Nationalsozialistische Außenpolitik, S. 701. 
durch auch unendlich viel notwendiger geworden und ich glaubte, mich einer Möglichkeit, dieser Sache noch weiter zu dienen, nicht verschließen zu dürfen."104 Seine Posten hätten ihm „die einzigen in einem autoritär geführten Staat bestehenden" Chancen eröffnet, die Idee der deutsch-französischen Aussöhnung wirksam weiterzuverbreiten ${ }^{105}$. Das suggeriert mutige Entschlossenheit, eine contre cœur betriebene Gleichschaltung der äußeren Existenz, um persönlichen Handlungsspielraum zu erlangen und einbringen zu können. Daß die zitierten Stellungnahmen aus einer Zeit stammen, da Abetz als Kriegsverbrecher angeklagt und inhaftiert war, legt natürlich den Schluß nahe, es handele sich um schlichte Schutzbehauptungen. Weggefährte Bran - „wenn man seine Sache bedroht sieht, dann erst recht" - bestritt dies auch 40 Jahre später entschieden: Wer die Nationalsozialisten „überlisten“ und in Deutschland ein kriegsverhütendes Sympathiepotential für Frankreich dadurch schaffen wollte, daß möglichst viele Angehörige beider $\mathrm{Na}$ tionen einander kennenlernten, der habe ungeachtet seiner inneren Überzeugung erst einmal die eigene Stellung im System festigen müssen ${ }^{106}$.

Verwandte Denk- und Verhaltensmuster entwickelten auch andere prominente Jugendbewegte, was geeignet erscheint, die Authentizität des von Abetz und Bran geschilderten Ansatzes zu stützen. Hermann Kügler aus Dresden, einer jener Freischarführer, die im März 1933 öffentlich vor dem wachsenden Druck der HJ kapitulierten, suchte gleichfalls Mittel und Wege, "die von uns begonnene Arbeit weiter zu tun. Ob und inwieweit das im Rahmen der nationalsozialistischen Herrschaft möglich sein würde, konnte nur experimentell festgestellt werden. " 107 Bündische, die Sachkenntnis und Gelegenheit besaßen, sollten deshalb "nach oben durchstoßen " und Breitenwirkung entfalten ${ }^{108}$. Der sprachenkundige, weitgereiste Kügler gelangte zunächst über Seilschaften in die Reichsleitung der Deutschen Studentenschaft, wo er das Hauptamt für Grenzland- und Außenpolitik übernahm. 1934 landete er wie Abetz im ,Büro Ribbentrop', hoffnungsvoll, im Gefolge des Mannes, der Hitlers Ohr in auswärtigen Fragen hatte, die künftigen Außenbeziehungen mitgestalten zu können. Intrigen rivalisierender Ämter setzten seiner Tätigkeit jedoch bald ein Ende ${ }^{109}$. Sein ehemaliger Stammesbruder in der „Sächsischen Jungenschaft", Ludwig Liebs, hat die Beeinflussungsstrategie, auf die sich Kügler wie Abetz beriefen, ausführlich erläutert und sie als einzig sinn-

104 Vernehmung durch John Fried, pag. 1. Fast wortgleich seine Einlassung vor Gericht am 12.7. 1949, pag. 34bis; AN, 334 AP 49.

105 Abetz, Das offene Problem, S. 40. Vgl. seine Aussage im Luchaire-Prozeß: ,j'étais décidé de défendre cette idée contre vents et marées “; Les procès de collaboration, $S$. 489.

106 Befragung Bran, 18. 3. 1989. Wie Abetz nimmt Bran das Motiv für sich in Anspruch, Partei und HJ beigetreten zu sein, um das deutsch-französische Verhältnis fortgesetzt günstig beeinflussen zu können.

107 Zit. in Kneip/Liebs/Zimmermann, Vom Geheimnis bündischer Führung, S. 143.

108 Diese Forderung knüpfte an die populäre Vorstellung an, daß sich bündisch sozialisierte Menschen langfristig in der Gesellschaft durchsetzen und dann ihren Einfluß für das ersehnte ,bündische Reich' geltend machen würden. Vgl.v. Hellfeld, Bündische Jugend und Hitlerjugend, S. 63, 68ff.

109 Jacobsen, Außenpolitik, S. 268f., basierend auf Mitteilungen Küglers aus dem Jahr 1966. Zu Küglers erzwungenem Ausscheiden aus der Dienststelle Ribbentrop siehe Kap. VI der vorliegenden Arbeit. 
volle Alternative zu innerer Emigration, Untergrundtätigkeit und Exil verteidigt. Da nicht abzusehen war, wie lange die NSDAP die Macht behaupten werde, sei es eine redliche, "politisch richtige Überlegung" gewesen, in HJ und Partei hineinzugehen, wo „alles im Fluß" war, so daß man "hoffen konnte, den Lauf dieses Flusses zu verändern, indem man hier und da kleine Dämme, harte Felsen, mühsam errichtete Mauern entgegensetzte [...] Es gehörte zum bündischen Wesen, daß man nicht einfach Gegebenes als unabänderlich hinnahm." Auf evolutionärem Weg sollte dafür gesorgt werden, daß ,in der nächsten Generation aus der Sache etwas anderes gemacht wird“. Nur aus taktischen Gründen habe man „das Odium der Kollaboration" nicht gescheut, dementierte Liebs opportunistische Hintergedanken: „Wer mit so gefährlichen Gegnern wie den Nationalsozialisten kämpft, muß auch einmal getarnt sprechen und Versionen finden, die es dem Gegner schwer machen, einen auszuschalten." 110

Exakt diesen Eindruck des berechnenden Mitläufers, der ideeller Ziele wegen Anpassung vortäuscht, hinterließ Abetz bei etlichen französischen Gesprächspartnern der Jahre 1933/34. Ihre Zeugnisse schildern seine Anbiederung ans NSRegime als anfänglich glaubhaften Versuch, ehrbaren Absichten trotz widriger Rahmenbedingungen treu zu bleiben. Der Frontkämpferführer Henri Pichot, bis wenige Monate vor Kriegsausbruch einer der zuverlässigsten und einflußreichsten Vermittler im deutsch-französischen Dialog, berichtet in seinen unveröffentlichten Memoiren über eine gemeinsame Autofahrt von Baden-Baden nach Kehl im August 1934, in deren Verlauf sich Abetz durchaus vertrauenswürdig als eine Art Trojanisches Pferd offenbarte, das in den Mauern Berlins postiert den Verfechtern einer Annäherung zum Durchbruch verhelfen wolle. Er habe, so Abetz, vor Jahresfrist gezaudert, sich dann aber gegen ein ungewisses, nutzloses Emigrantendasein in Paris und für verdeckte, geduldige Überzeugungsarbeit innerhalb des NS-Apparats entschieden, wozu ihm seine jetzige Verwendung aussichtsreiche Möglichkeiten biete. Mit der Partei habe er nichts zu schaffen, doch glaube er an Hitlers Friedfertigkeit. Sollte diese Überzeugung eines Tages schwinden, werde er eilends Alarm schlagen - ein niemals eingelöstes Versprechen ${ }^{111}$. Auch André Weil-Curiel zufolge wollte Abetz 1933 emigrieren, worauf er ihn bedrängt habe, in Deutschland zu bleiben: „Nous n'avons pas besoin d'un émigré de plus ici, mais d'hommes comme toi qui puissent expliquer à tes compatriotes que les Français ne

110 Liebs, „Die Bündischen und die Hitlerjugend. Auflösung und Verbot der Bünde 1933“, Vortrag, gehalten Pfingsten 1965 in Höchst/Odenwald auf einer Tagung des Boberhauskreises e.V. und des Sachsenkreises im Freideutschen Konvent, abgedruckt in: ders., Schirach, Marx und Moralisten, S. 18-36; vgl. "Offener Brief an Baldur v. Schirach“, 31. 10. 1967, ebenda, S. 11-15. Ähnliche Hintergedanken deklamierten hochrangige Diplomaten, die in verbrecherische Machenschaften des Nazi-Regimes verstrickt wurden. Nach seiner Ernennung zum stellvertretenden Leiter der Politischen Abteilung des AA 1936 sagte Ernst v. Weizsäcker einem Freund, „nachher werde es so aussehen, als sei man dabei gewesen [...]; aber dieses Odium müsse man auf sich nehmen um des einen Zieles willen, vielleicht den Frieden zu retten". v. Weizsäcker, Erinnerungen, S. 127.

111 Pichot, Et ce fut quand même la guerre, handschriftl. Manuskript und masch. Abschrift (107 S. und Anm.), unterzeichnet „Orléans, 20 août-15 septembre 1944“, pag. 16; AN, 43 AS 5 (Nachl. Pichot). 
sont pas tous des ogres qui veulent dévorer l'Allemagne."112 An Abetz' Aufrichtigkeit zum damaligen Zeitpunkt hegt er nicht den geringsten Zweifel ${ }^{113}$. Erst allmählich und zunächst kaum wahrnehmbar, so Curiels Beobachtung, verbogen wachsender Einfluß und gesellschaftlicher Aufstieg den Charakter des Freundes, verzahnte sich dieser im braunen Räderwerk. Unfähig, Lüge und Wahrheit in den Friedensappellen der Berliner Führung zu unterscheiden, sei er schließlich ein versierter Handlungsreisender in Sachen nationalsozialistische Frankreichpolitik geworden. Ganz ähnlich urteilte Alfred Silbert, in dessen Augen Abetz die Hitlerbewegung für unwiderstehlich hielt und sich in der Hoffnung mitreißen ließ, persönlich und für die deutsch-französische Annäherung etwas erreichen zu können. Damit einher ging eine schleichende Entfremdung: „Son appartenance au régime nazi le mettait en opposition de plus en plus directe, de plus en plus nette avec les idées que j'éprouvais moi-même." 114

Jules Romains, beeindruckt, daß materielle Interessen beim Wechsel vom Rhein an die Spree offensichtlich keine Rolle spielten, war 1934 nach eingehenden Gesprächen mit Abetz überzeugt, „qu'il n'était pas nazi, et même qu'il eût souhaité

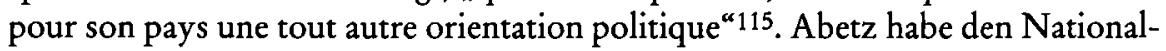
sozialismus als „blinde Kraft" ohne eindeutige Stoßrichtung charakterisiert, eine Art Gewitterwolke, die Deutschland und Europa überquere und geschickt gelenkt werden müsse, damit sie keine irreparablen Schäden anrichte ${ }^{116}$. „Nous nous sommes voués à la même cause vous et moi“', zog er Romains ins Vertrauen, „celle de la paix à sauver, et là où elle est le plus menacée, entre la France et l'Allemagne; et nous avons trouvé le même obstacle sur notre route, ou la même énigme: le phénomène nazi. Vous, vous êtes au dehors; moi, je suis à l'intérieur [...] Il faudrait s'arranger pour travailler dans le même sens, et en liaison [...] Vous pouvez compter sur moi. "117 Das klang verschwörerisch, komplizenhaft, ließ den Sprecher wie einen fleischgewordenen ,homme de bonne volonté aus Romains' Romanwelten erscheinen. Der Dichter jedenfalls zweifelte nicht, daß sein deutscher Freund die Wahrheit sprach, und schöpfte Zuversicht aus der Vorstellung, Abetz werde an „seinem kleinen Platze" stets "wie ein verborgener Sauerteig wirken“"118. "Je ne puis pas croire qu'ils m'aient menti, lui et sa femme", schrieb er $1940 \mathrm{im}$ New Yorker Exil, halb resigniert, halb verständnisvoll ergänzend, im ,Dritten Reich' ein rundum integrer Mensch zu bleiben sei wohl ungefähr so schwierig wie die Wahrung des Keuschheitsgelübdes in einem Freudenhaus ${ }^{119}$.

Man mag einwenden, daß die angeführten Zeugen dem NS-Regime jahrelang

112 Weil-Curiel, Eclipse en France, S. 125.

113 „La sincérité d'Otto Abetz pendant les années 33-35 ne peut faire aucun doute pour ceux qui l'ont bien connu [...] Il avait foi dans la logomachie pacifiste du Führer"; ebenda, S. 126.

114 Zeugenaussage Silberts im Abetz-Prozeß, 19.7. 1949, pag. 57; AN, 334 AP 49.

115 Romains, Sept mystères, S. 225.

116 Ebenda, S. $225 \mathrm{f}$.

117 Ebenda, S. 227.

118 Romains, The Mystery of Ribbentrop \& Co., in: The Saturday Evening Post, 16. 11. 1940, deutsche Übers. bei den Akten der Dienststelle Ribbentrop; PA/AA, R 27159.

119 Ders., Sept mystères, S. 275 f. 
sehr aufgeschlossen begegneten, was ein zu positives Urteil über Abetz gewiß begünstigen konnte. Anderseits ist bemerkenswert, daß die Überlieferungen allesamt aus einer Zeit datieren, da die Autoren ihr Vertrauen mißbraucht sahen und längst auf Distanz gegangen waren. Dessen unbeschadet sind sie um ein differenziertes Persönlichkeitsbild bemüht, anstatt den Deutschen einfach als abgefeimten Lügner bloßzustellen, dem sie aufgesessen waren, was ihre im nachhinein töricht anmutende Gutgläubigkeit kaschiert hätte. Sollte Abetz sie mit seinen Behauptungen tatsächlich düpiert haben, ging er mit erschreckender Skrupellosigkeit zu Werke. Anderenfalls überzeichnen Charakterskizzen, wonach er den französischen Wehrwillen von Anbeginn heimtückisch untergrub ${ }^{120}$. In jedem Fall zu kurz aber greifen Beschreibungen, die einen Naivling ohne politischen Instinkt präsentieren ${ }^{121}$. Er erkannte seine Chance, auch künftig im deutsch-französischen Dialog mitmischen zu können, und griff zu. Just zu einem Zeitpunkt, da die Strahlkraft des Sohlbergkreises zu versiegen drohte, eröffneten sich neue Entfaltungsmöglichkeiten, sofern die Braunhemden ihn akzeptierten. Wie sich rasch herausstellte, waren die von ihm feilgebotenen Kenntnisse und Fähigkeiten sogar regelrecht begehrt, denn er besaß, woran es den Nationalsozialisten mangelte, was sie jedoch im Zeichen einer taktisch akzentuierten Entspannungspolitik dringend benötigten: funktionstüchtige Kanäle zu verständigungsbereiten Franzosen.

Diese Konstellation beförderte Abetz, schmeichelhaft für sein Ego, unversehens in den Rang eines anerkannten Spezialisten. Auffällig unpolitisch gehaltene Erklärungen Schirachs vermittelten das Gefühl, in Sachen Völkerverständigung bei der Reichsjugendführung gut aufgehoben zu sein. „Hitlerjungen, die ins Ausland fahren, reisen nicht als Propagandisten des Nationalsozialismus", verkündete der Jugendführer des Deutschen Reiches, „ihre Aufgabe ist nicht lehren, sondern lernen. Sie sollen die Schönheit der fremden Landschaft erleben und die nationale Eigenart des Gastlandes erkunden. "Im übrigen wünsche Deutschland, daß Heranwachsende „möglichst frühzeitig andere Nationen kennen und achten lernen“. Auf dieser Grundlage sei eine fruchtbare Zusammenarbeit im europäischen Maßstab möglich, die Menschen könnten "gerechter werden “122. Da wurde sie wieder beschworen, jene frieden- und einheitstiftende Gestaltungskraft der jungen Generation, auf die die "Freunde des Sohlbergcamps" so große Hoffnungen gesetzt hatten. Abetz' Anfälligkeit für solche Parolen erscheint evident. Als RJF-Referent, mehr noch in Diensten Ribbentrops durfte er sich zudem nach jugendbewegter Manier einem Orden zugehörig fühlen, aus der Masse herausgehoben und Idealen verpflichtet ${ }^{123}$. An Mythen wie Reich und Volksgemeinschaft gekoppelte Vorstellungen, die in Kreisen der Jugendbewegung höchst lebendig waren und von den verführerisch jugendbetont agierenden Nationalsozialisten kultiviert wurden, konnten eine ideelle Kooperationsgrundlage vorspiegeln; ebenso die re-

120 Vgl. etwa Shirer, Zusammenbruch Frankreichs, S. 433, 461; Paillole, Services spéciaux, S. 145 f.; Thalmann, Du cercle de Sohlberg.

121 Vgl. zum Beispiel Laqueur, Deutsche Jugendbewegung, S. 264, 266; v. Schramm, Hitlers psychologischer Angriff, S. 53.

122 v. Schirach, Hitler-Jugend, S. $155 \mathrm{f}$.

123 Vgl. Kap. III.3 der vorliegenden Arbeit. 
visionistischen, Gleichberechtigung einfordernden Ziele deutscher Außenpolitik, die seit Kriegsende opinio communis waren und die zunächst auch Hitlers Regierung in einem zwar macht- und nationalbewußt geführten, aber doch auf friedliche Koexistenz gerichteten Dialog anzupeilen schien, der Abetz als ausgleichfördernde Determinante in den deutsch-französischen Beziehungen vorschwebte ${ }^{124}$.

Vermeintliche Interessenkongruenz und kurzfristige Entwicklung verleiteten zu verhängnisvollen Trugschlüssen. Der Journalist Wladimir d'Ormesson, der Abetz und Bran Anfang 1935 in Paris interviewte, beschrieb sie als idealistische Gemüter, die nach all den Miseren und Rückschlägen der jüngsten deutschen Vergangenheit in Hitler eine Art Heilsbringer sahen, der für Jugend, Tatkraft, die Lösung wirtschaftlicher und sozialer Probleme und nicht zuletzt für Frieden mit Frankreich stand ${ }^{125}$. Die Umwälzung in Deutschland sei von 1934 an moderater verlaufen, gab Abetz später seine Eindrücke wieder. Besonders die Initiativen auf gesellschafts- und sozialpolitischem Gebiet hätten dem Regime die Zustimmung jedes fortschrittlich denkenden jungen Deutschen gesichert; Projekte seien angeschoben worden, die sich die demokratisch regierten Länder zum Vorbild nehmen mochten ${ }^{126}$. Bezüglich der deutschen Frankreichpolitik beruhigte ihn, daß ,Annäherung' unter Hitler sich nicht auf effektheischende offizielle Verlautbarungen zu beschränken schien, sondern, von amtlicher Seite ermutigt, in weiten Bevölkerungskreisen, unter Jugendlichen wie unter den Millionen Mitglieder zählenden Frontkämpferverbänden beider Länder, praktiziert werden durfte ${ }^{127}$. Aus diesem Blickwinkel schienen totalitäre Strukturen sogar spezifische Vorzüge zu bieten: Es galt die „führenden Leute" für eine Idee zu begeistern - die "Schafe" würden dann automatisch den "Leithammeln" folgen ${ }^{128}$. Umgekehrt, spekulierte Abetz, konnte eine dergestalt ins Werk gesetzte Massenbewegung den Verständigungsgedanken so tief in der Bevölkerung verankern, daß selbst eine kriegslüsterne Regierung darauf Rücksicht nehmen müßte, worin er ,une garantie précieuse pour l'avenir" erblickte ${ }^{129}$. Der Umfang, in dem ein solcher Prozeß von Staats wegen

124 Vgl. Liebs' Analyse: „daß eine vernünftige Ordnung der Volksgruppen in Europa versucht werden müsse, [...] schien uns in Ordnung zu sein [...], und da Hitler und seine Leute immer wieder betonten, daß sie ihre Ziele in Frieden erreichen wollten, [...] durfte man damals - so unglaublich das heute erscheint - hoffen, daß dort Möglichkeiten sinnvoller Einwirkung vorhanden wären ". Schirach, Marx und Moralisten, S. 28.

125 d'Ormesson, Quelle Allemagne?, in: Le Figaro, 8. 2. 1935. François-Poncet konstatierte etwa zum selben Zeitpunkt in der Umgebung Schirachs „un désir sincère de rapprochement et de collaboration". Namentlich erwähnte er in diesem Zusammenhang auch Abetz. Seine Empfehlung: „Ces efforts, qui semblent répondre à une conviction sincère, méritent certainemaint d'être encouragés." Sollte die Reichsjugend allerdings weiterhin derart dezidiert nationalistisch erzogen werden, seien nur geringe Ergebnisse zu erwarten. François-Poncet an Ministère des Affaires Etrangères, 9.4. 1935; MAE, Europe 1918-1940, Allemagne 755, Bl. $186 \mathrm{f}$.

126 "Circonstances de l'adhésion d'Otto Abetz au National-Socialisme“, pag. 5; AN, F 7/ 15331.

127 Ebenda, pag. 6.

128 Vernehmung durch John Fried am 28. 5. 1947; StA Nürnberg, KV-Anklage, Interrogations, A 2.

129 Verhörprotokoll Nr. 204/8 der Renseignements Généraux vom 26.11. 1945, „Déclarations d'Otto Abetz au sujet de ses activités propagandistes"; AN, F 7/15331. Friedrich 
zugelassen wurde, dünkte ihn ein sicherer Gradmesser dafür, inwieweit der ,Führer ${ }^{夭}$ aufrichtig ein Einvernehmen mit Frankreich wünschte ${ }^{130}$. Besonders Hitlers Regierungserklärung vom 17. Mai 1933 schien zu einigem Optimismus zu berechtigen. „Indem wir in grenzenloser Liebe und Treue an unserem eigenen Volkstum hängen“, sprach der Kanzler, „respektieren wir die nationalen Rechte auch der anderen Völker aus dieser selben Gesinnung heraus und möchten aus tiefinnerstem Herzen mit ihnen in Frieden und Freundschaft leben." ${ }^{\text {131 }}$

\section{Strategie der Selbstverharmlosung: Hitlers Frankreichpolitik}

Dic Realität sah, wie die Welt leidvoll erfahren sollte, anders aus. Zunächst aber war Hitler jedes Mittel recht, die um ihre Sicherheit fürchtenden Nachbarn im Westen zu beschwichtigen. Er wollte Zeit gewinnen, um seine Herrschaft in Deutschland zu konsolidieren, eine schlagkräftige Armee aufzubauen und das gegnerische Bündnissystem zu schwächen - Voraussetzungen einer expansiven Außenpolitik, die zu betreiben er rückhaltlos gewillt war. „Diese Erde ist niemandem zugeteilt", lautete eine seiner Maximen ${ }^{132}$. Krieg und Gewalt betrachtete er als unverzichtbare Komponenten im permanenten Lebenskampf eines Volkes, und „was der Güte verweigert wird, hat eben die Faust sich zu nehmen"133. Besonders in den Jahren 1933 bis 1935 mußte Hitler, der seinen abgrundtiefen Haß gegen die Franzosen nie verhehlt hatte, jedoch damit rechnen, daß sie seine Rechnung durchkreuzten. Mit Blickrichtung Paris warnte er am 3. Februar 1933 vor Befehlshabern von Heer und Marine, die sich beim Freiherrn v. HammersteinEquord versammelt hatten: „Die gefährlichste Zeit ist die des Aufbaus der Wehrmacht. Da wird sich zeigen, ob Frankreich Staatsmänner hat; wenn ja, wird es uns die Zeit nicht lassen, sondern über uns herfallen. " 134 Um Präventivschläge der vorerst noch stärksten Militärmacht Europas und ihrer Verbündeten gegen die illegale, aber kaum geheimzuhaltende deutsche Aufrüstung zu verhindern, gab sich Hitler fortan betont friedfertig, schwenkte um von der "programmatischen

Bran bestätigte und bekräftigte diese Überlegung während unseres Gesprächs am 18. 3. 1989. Als Teilerfolg seiner Bemühungen, die in die Erziehungsarbeit der $\mathrm{HJ}$ eingeflossen seien, wertete Abetz das nach seinen Beobachtungen außerordentlich ritterliche Verhalten junger deutscher Soldaten während des Westfeldzugs 1940; Das offene Problem, S. 40 .

130 Ebenda, S. 39.

131 Domarus, Hitler, I, S. 273. Shirer, Aufstieg und Fall des Dritten Reiches, S. 206, nannte diese Rede ein "Meisterstück irreführender Propaganda“. André Gide notierte am 20. Mai 1933: „Si le hitlérisme ne s'était jamais fait connaître autrement, il serait mieux que simplement acceptable“; Journal, S. 1169.

132 Hitlers Zweites Buch, S. 55.

133 Hitler, Mein Kampf, S. 152.

134 Aus einer Aufzeichnung des Generalleutnants Liebmann, abgedruckt bei Vogelsang, Neue Dokumente zur Geschichte der Reichswehr, S. 435. Auch Goebbels hätte ein solches Einschreiten „durchaus logisch“ gefunden, wie er im April 1940 vor deutschen Journalisten einräumte; zit. bei Hillgruber, Hitlers Strategie, S. 14. 
Verkündung auf die diplomatische Vorbereitung" seiner außenpolitischen Pläne, die er in den Jahren 1925 bis 1928 schriftlich niedergelegt hatte und, wenngleich stets zur Anpassung an veränderte Konstellationen bereit, im Kern „über alle Wechselfälle seines Lebens hinweg bis zum Ende ${ }^{\star}$ verfolgte ${ }^{135}$. Die Vernichtung Frankreichs, "unerbittlicher Todfeind des deutschen Volkes"136, besaß nun, anders als in den frühen zwanziger Jahren, keinen Zielcharakter mehr an sich, sondern „programmatische Hilfsfunktion "137, wurde Mittel zum Zweck in einem viel weitgreifenderen Unternehmen: Der westliche Nachbar sollte zu gegebener Zeit ausgeschaltet werden, um den Rücken frei zu bekommen für die Eroberung von ,Lebensraum' im Osten, wo Rußland, nach Hitlers Einschätzung ein Koloß auf tönernen Füßen, leichte Beute sein würde ${ }^{138}$.

1933 war dies kein öffentliches Thema. Der ,Führer hütete sich, das Mißtrauen des beunruhigten Auslands weiter zu schüren. Er war gewarnt. Deutschlands Botschafter in Paris, Roland Köster, meldete am 11. März einen „überall deutlich bemerkbaren Umschwung zu unseren Ungunsten "139. Außenminister v. Neurath meinte, Revisionen könnten erst avisiert werden, wenn das Reich seine "gefährliche Schwäche" überwunden habe. Bis dahin müsse man sich mit wirksamer Propaganda auf der Grundlage der Wilsonschen Punkte begnügen. „Alles, was wir erreichen können, ist, daß uns Frankreich nicht in den Arm fällt." Die Erfahrung lehre allerdings, „daß sich die Franzosen mit einer nicht allzu stürmischen Entwicklung abfinden"140. So praktizierte Hitler in der Folge eine „Strategie grandioser Selbstverharmlosung "141, bis er zum Krieg gerüstet war. Es handelte sich um eine sorgfältig dosierte Mischung aus vorgetäuschter Sanftmut und Aggression. Während er einerseits beharrlich die Sehnsucht seines Volkes nach Ruhe und Frieden hervorhob, desgleichen den Anspruch, Europa vor dem Bolschewismus zu retten, und versicherte, daß der Nationalsozialismus keine Exportware sei, forcierte er gleichzeitig die Aufrüstung, suchte offensive Bündnisse zu schmieden, drohte und annektierte. Jedem Anschlag auf den Status quo folgten prompt ein Schwall versöhnlicher Worte, mit Bedacht stets bilateral gehaltene Verhandlungsofferten - ohne daß er sich je auf ernsthafte vertragliche Abmachungen mit Frankreich eingelassen hätte - und das Gelöbnis, die Aktion habe lediglich zur Wiederherstellung der vollen Souveränität und nationalen Ehre gedient ${ }^{142}$. Er verstand es

135 Jäckel, Frankreich in Hitlers Europa, S. 24, 27. Vgl. Steinert, Hitler, S. 346; Bloch, Aspekte der Beziehungen zwischen dem Dritten Reich und Frankreich, in: Büttner (Hrsg.), Das Unrechtsregime, I, S. $489 \mathrm{ff}$.

136 Hitler, Mein Kampf, S. 699.

137 Knipping, Frankreich in Hitlers Außenpolitik 1933-1939, in: Funke (Hrsg.), Hitler, Deutschland und die Mächte, S. 615.

138 Hitler, Mein Kampf, S. 741 ff., 766f. Zur ebenso verbreiteten wie fatalen Unterschätzung der machtpolitischen Visionen Hitlers im In- und Ausland Hildebrand, Das vergangene Reich, S. $575 \mathrm{ff}$.; Lange, Hitlers unbeachtete Maximen.

139 Köster an Auswärtiges Amt, 11. 3. 1933; ADAP, C I.1, Nr. 70.

140 Aufzeichnung Thomsen vom 7. 4. 1933, ebenda, Nr. 142.

141 Jacobsen, Außenpolitik, S. 328.

142 Ein frühes Paradebeispiel ist Hitlers Rundfunkansprache am 14. Oktober 1933, gekoppelt mit einem Aufruf an das deutsche Volk - Stunden zuvor hatte die Reichsregierung den deutschen Rückzug vom Völkerbund und von der Genfer Abrüstungskonferenz be- 
meisterhaft, sich als ewig mißverstandenen Anwalt eines entrechteten Volkes zu stilisieren, pochte zudem vorläufig auf Forderungen, die schon seine Vorgänger im Amt erhoben hatten und die im eigenen Lager gemeinhin als legitimer Ausdruck nationaler Selbstbehauptung interpretiert wurden. Auch das erschwerte „eine Unterscheidung des Maßvollen vom Maßlosen"143. Je mehr Franzosen trotzdem an die deutsche Friedfertigkeit glaubten, desto ungestörter konnte Hitler seine Feldzüge planen. Was also lag näher, als die reichlich vorhandenen pazifistischen Strömungen im Nachbarland auszubeuten, indem man Männer wie Abetz vorschickte, die sich seit Jahren um Annäherung bemühten und zumindest über jeden Zweifel erhaben schienen, Kriegstreiber zu sein, die auch ganz und gar nichts Fanatisches an sich hatten. Abetz' vielfältige persönliche Kontakte kamen überdies Hitlers Neigung entgegen, seine Botschaften an den engen diplomatischen Kanälen vorbei möglichst breitgefächert unters französische Volk zu streuen und so das Echo zu verstärken. In diesem Kontext war er ein nahezu ideales Medium für die „pazifistische Platte“ des Kanzlers ${ }^{144}$.

\section{5. „Freundschaft“ gegen Machtverzicht: Abetz als Interpret der NS-Führung}

Doch nicht nur Abetz verkannte zunächst, welchen Kurs Hitler tatsächlich steuerte, daß es sich um einen Friedenswillen auf Zeit handelte und Verständigungsinitiativen einstweilen gefördert wurden, weil sie politisch nützlich waren. Bis sich die maßlosen Ziele des ,Führers', die an Traditionslinien deutscher Außenpolitik anknüpften, sie in ihrer Radikalität und rassenideologischen Begründung jedoch weit übertrafen ${ }^{145}$, unzweideutig abzeichneten, war der Karlsruher freilich längst ins nationalsozialistische System eingebunden und zur Schlüsselfigur eines psychologischen Feldzugs gegen Frankreich geworden, sein kometenhafter Aufstieg zu einem der wichtigsten Mitarbeiter Ribbentrops einhergegangen mit wachsendem Verlust an innerer Distanz zum Regime und kritischer Reflexion. Im selben Maße erodierte seine persönliche Integrität, verschwammen die Trennlinien zwischen Idealismus und Berechnung, Aufrichtigkeit und Doppelmoral, sachlicher Information und propagandistischer Finte. Ursprünglich honorige Ambitionen wurden zusehends von einer bestürzenden Unempfindlichkeit gegenüber nationalsozialistischen Machenschaften überlagert, angestrengt legitimiert durch den zur Illusion verurteilten Vorsatz, durch aktives Mitläufertum ge-

kanntgegeben. Siehe Domarus, Hitler, I, S. 311 f., und ADAP, C II.1, Nr. 1. Hildebrand, Das vergangene Reich, S. 608, nennt das außenpolitische Lavieren zwischen einvernehmendem Werben und kaum verhüllter Gewaltbereitschaft einen „diabolischen Schachzug“, der bis Ende 1938 ein ums andere Mal verfing.

143 Jacobsen, Außenpolitik, S. 338. Zum verdeckten „Auftakt zur Expansionspolitik im Gewande traditioneller Revisionsforderungen" siehe auch Messerschmidt, Außenpolitik und Kriegsvorbereitung, in: Deist u. a., Ursachen und Voraussetzungen, S. $670 \mathrm{ff}$.

$144 \mathrm{Vgl}$. v. Schramm, ... sprich vom Frieden, S. $45 \mathrm{ff}$.

145 Hierzu Hildebrand, Hitlers Ort, bes. S. 615 ff. 
genzusteuern. Aus dem um Sympathie werbenden Animateur, der aus gegenseitigem Sichkennenlernen gegenseitiges Verständnis - auch und gerade für deutsche Gravamina - ableitete, wurde ein kompromißloser Propagandist, der fragwürdigste Ansprüche und Entscheidungen seiner Regierung interpretierte und verteidigte, ein Verführer, der eine prodeutsche Lobby im Nachbarland zimmerte, indem er Prädispositionen für eine Zusammenarbeit mit dem ,Dritten Reich ' Friedenssehnsucht, Unzufriedenheit mit den innenpolitischen Verhältnissen, Neugier, mehr oder weniger offen gehegte Bewunderung, Bestechlichkeit - aufspürte, auslotete und ausnützte; die nachfolgenden Kapitel bieten hierzu reichhaltiges Anschauungsmaterial.

Methodisch subtile, inhaltlich stereotype Kampagnen, in Diensten Ribbentrops lanciert, schoben vordergründig tatsächlich eine breite Verständigungsbewegung an, erschöpften sich letztlich aber darin, die Franzosen dazu zu bringen, deutschen Expansionswünschen im Interesse friedlicher Koexistenz nicht länger im Wege zu stehen - ein durch Hitlers Taten immer schonungsloser bloßgestelltes Wortgeklingel, das Abetz, seinem Ruf und Realitätssinn gleichermaßen abträglich, ebenso ungeahnte wie fragwürdige Triumphe als "Mittler" ermöglichte. Objektiv besehen, leistete er von 1933 an einer Politik Vorschub, die Frankreich destabilisieren und ein ungehemmtes deutsches Ausgreifen vorbereiten sollte. Verständigung im Sinne gleichberechtigter Partnerschaft konnte hieraus nicht erwachsen, allenfalls Unterwerfung. Der Mann, der die Nazis „überlisten“ wollte, finassierte immer dreister gegen jene, auf deren Seite zu stehen er vorgab, was er nach dem Krieg in einer Mischung aus Selbstschutz und Selbstbetrug vehement bestritten hat. Sein ursprüngliches Anliegen, ein Miteinander beider Länder zu fördern, blieb, so paradox es klingt, bei all dem prinzipiell unberührt, was die eigentümliche Zwiespältigkeit seiner Bemühungen ausmacht und schlaglichtartig erhellt. Denn die Voraussetzungen für ein Rapprochement wandelten sich dramatisch zu Lasten Frankreichs, dem die Preisgabe immer weiterer machtpolitischer Positionen, zuletzt fast bedingungsloses Stillhalten abverlangt wurde, eine Entwicklung, die 1940/41 in vagen Offerten der Berliner Führung kulminierte, für politisch-militärische Botmäßigkeit mit der Rolle eines „Juniorpartners“ im deutsch beherrschten Europa entlohnt zu werden. Den Anspruch, Korrektiv nationalsozialistischer Frankreichpolitik zu sein, hielt Abetz ebenfalls unentwegt aufrecht. Vor Gericht verstieg er sich in die phantasievolle Allegorie vom Sankt-Gotthard-Expreß, der mit defekten Bremsen scheinbar unaufhaltsam talwärts braust. Ein einfacher Mechaniker will die Katastrophe verhindern und fährt dem außer Kontrolle geratenen Zug mit einer Rangierlok entgegen, wird aber eine weite Strecke mitgerissen, ehe eine Bremswirkung einsetzt. In ähnlicher Manier, so Abetz, sei es ihm zeitweise gelungen, Hitlers Sturm und Drang gegen Frankreich abzuschwächen, ,jusqu'à l'arrêt dans la gare de Montoire“146.

146 Abetz-Prozeß, 13. 7. 1949, pag. 6ff.; AN, 334 AP 49. In ähnlicher Weise - ein Zufall? hatte schon der Zentrumsabgeordnete und frühere badische Staatspräsident Heinrich Köhler nach dem nationalsozialistischen Erdrutschsieg bei der Reichstagswahl am 14. September 1930 gegenüber Reichskanzler Brüning argumentiert: Zur Frage, ob die NSDAP nun an der Macht zu beteiligen wäre, meinte Köhler, „in Baden habe man es in 
Ein gleichwertige Partnerschaft negierender Erwartungshorizont schlich sich wie eine Unwucht bald auch in Formulierungen von Abetz ein, die nicht für den internen Gebrauch bestimmt, sondern öffentlich nachzulesen waren. Auf die Vorbildfunktion mittelalterlicher Eintracht und gemeinsamer kultureller Wurzeln des Abendlandes rekurrierend, ein Lieblingsthema, das auch Jules Romains im November 1934 bei einem vom Sohlbergkreis organisierten Vortrag in Berlin aktualisierte, indem er einer künftigen Allianz postimperialistischer, ihrer Eigenarten bewußter Nationalismen das Wort redete ${ }^{147}$, schrieb er zu Jahresbeginn 1935 in den Deutsch-Französischen Monatsheften: „Là où l'Occident a été grand, il l'a été grâce à l'équilibre harmonieux de la force germanique et de la forme latine “148 ein ebenso versteckt plazierter wie aufschlußreicher Satz, der andeutet, in welche Richtung sich sein Rollenbild der beiden Länder schon damals bewegte. Daß ihm Hitlers doppeltes Spiel auf Dauer keineswegs verborgen blieb, enthüllt eine Denkschrift vom Juli 1940. Darin empfiehlt Abetz, den Franzosen eine fortwährende militärische Präsenz der deutschen Siegermacht auch durch verstärktes Abheben auf den Europa-Gedanken schmackhaft zu machen. Das würde den „kontinentalen Führungsanspruch“ des Reiches nicht schmälern - „genau so wie der Friedensgedanke vom nationalsozialistischen Deutschland usurpiert wurde und zu einer moralischen Schwächung Frankreichs führte, ohne dem kämpferischen Geiste Deutschlands Abbruch zu tun "149. Dieses die häufig beteuerte Verbundenheit mit Frankreich desavouierende Eingeständnis vor Augen, hätte er sich - theoretisch - weiterer exponierter Mitarbeit im NS-Staat versagen können (über mögliche persönliche Konsequenzen einer solchen Weigerung läßt sich nur spekulieren). Mit fortlaufender Tätigkeitsdauer aber vergröberte sich sein Verständigungsanspruch fast $z$ wangsläufig. Bald ging es bestenfalls darum, die Franzosen nachgiebig zu stimmen oder sie ideologisch zu vereinnahmen, bis 1939 zur Verhinderung kriegerischer Verwicklungen, von Juni 1940 an, um Härten der deutschen Besatzung zu mildern bzw. eine militärische Entente zu ermöglichen. Nationalsozialistische Machtansprüche und die deutsch-französische Annäherung zu forcieren, Hitler zu dienen und gleichzeitig seinen finsteren Plänen zuwiderlaufende Positionen durchzusetzen, erwies sich als Quadratur des Zirkels. So wirken viele von Abetz erzielte Resultate im nachhinein wie unselige Karikaturen seiner erklärten Absichten.

Als Frankreichreferent der RJF bemühte sich Abetz mit gewohntem Elan, aber durchwachsenem Erfolg, die Beziehungen zwischen Hitlerjugend und französischen Verbänden zu intensivieren. Eine Aufzeichnung des Auswärtigen Amts do-

dieser Beziehung immer mit dem Windthorstschen Grundsatz gehalten, wenn eine Lokomotive dahergebraust komme, sich ihr nicht einfach in den Weg zu stellen, sondern zu versuchen aufzuspringen und an oder mit an den Führersitz zu kommen“. Köhler, Lebenserinnerungen, S. 300 .

147 Romains, Latinität und Germanentum, in deutscher Übers. abgedruckt DFM, Dezember 1934, S. 47-63.

148 Abetz, A la recherche de l'Occident, in: DFM, Januar-Februar 1935, S. 116 (Hervorhebungen durch den Verf.).

149 Abetz, "Politische Arbeit in Frankreich“, 30.7.1940 (Abschr.); CDJC, LXXI-28, pag. 11. Das Zitat ist im Original unterstrichen. 
kumentiert beispielhaft den Stand seiner Bemühungen und Projekte im Februar 1935: In Planung waren ein deutsch-französisches Skilager bei Chamonix Ende des Monats, ein Aufenthalt deutscher Jugendführer in Paris, wo sie über Ostern mit französischen Kameraden „Probleme der sozialen und wirtschaftlichen Fürsorge in beiden Ländern" diskutieren sollten, zu Pfingsten ein Gegenbesuch in Berlin mit Besichtigung von Betrieben und sozialen Einrichtungen sowie eine deutsch-französische "Jugendwanderfahrt" mit Lager. Darüber hinaus, berichtete Abetz, sei bei den jüngsten Besprechungen mit französischen Jugendvertretern Ende Januar ein Druckschriftenaustausch vereinbart worden, "wovon sich die Reichsjugendführung namentlich eine verstärkte Absatzmöglichkeit ihrer Zeitschrift Soblbergkreis verspricht" 150 . Bran und Nabersberg, die bei den Verhandlungen assistierten, nannten als Richtschnur ihrer Sondierungen, „ohne Rücksicht auf die französische Innenpolitik möglichst zu allen Kreisen der Jugend persönliche Verbindungen herzustellen“. Hierdurch sollte eine Atmosphäre geschaffen werden, die sich „zu gegebener Zeit von den für die Außenpolitik zuständigen Organen" zum Nutzen des Reiches auswerten ließ151. Die Vereinnahmung und Instrumentalisierung der Jugendkontakte durch das Hitler-Regime wird nicht nur an dieser Stelle offenkundig. Die vom Sohlbergkreis kultivierte Kommunikationsform des vertieften, meinungsintensiven Dialogs erwies sich unter nationalsozialistischen Prämissen als Auslaufmodell und kam letztmals im April 1935 bei einer von Abetz und dem "Comité de la jeunesse française pour le rapprochement franco-allemand" organisierten wirtschaftspolitischen Aussprache in Paris zum Zuge.

An dieser Tagung nahmen von deutscher Seite vier Angehörige der RJF (drei von der Abteilung Ausland, einer vom Amt für Soziales) und je drei Delegierte der Studentenschaft und der Jungjuristen im NS-Juristenbund teil. Sie trafen auf ein abermals buntgemischtes französisches Publikum, zusammengesetzt aus Repräsentanten linksgerichteter Verbände (Jeunesses socialistes, Jeunesses radicales, Jeunesses laïques et républicaines, Etudiants pour la Société des Nations), rechter Organisationen (Jeunesses patriotes, Croix de Feu, Action Française), Vertretern von Mouniers Esprit-Gruppe und der "Etats généraux de la jeunesse"152. Die Hauptreferate hielten ein Oberbannführer Stadler und Paul Marion, führender Kopf bei den Neosozialisten und künftiger Informationsfachmann der Vichy-Regierung. Außenpolitische Themen, so Abetz in einem längeren Bericht, seien

150 Aufzeichnung v. Rintelen (AA) über eine Unterredung mit Abetz, 12. 2. 1935; PA/AA, Botschaft Paris 1050/1. Die zweisprachige Revue, Nachfolgerin der „Blätter des Sohlbergkreises", erschien seit Ende 1934 im zweiten Jahrgang mit dem Untertitel DeutschFranzösische Monatshefte - Cahiers Franco-Allemands; Näheres siehe Kap. IV.

151 Aktenvermerk Forster (Botschaft Paris), 30. 1. 1935; PA/AA, Botschaft Paris 1050/1.

152 Die Etats généraux waren auf Initiative des Luchaire-Jouvenel-Kreises Ende Juni 1934 in Paris gebildet worden. Alle französischen Jugendorganisationen mit Ausnahme der kommunistischen sollen zugange gewesen sein. Erwartungen, daraus könne ein handlungsfähiger Dachverband entstehen, erfüllten sich nicht, die Etats généraux spielten im folgenden zumindest für die deutsch-französischen Beziehungen keine Rolle. Abetz hatte sich auf der Gründungsversammlung als Delegierter der deutschen Jugend präsentiert. Bericht der Sûreté Nationale vom 7. 12. 1934, ${ }_{n}$ Au sujet de Jean Luchaire et des Allemands ${ }^{\star}$; AN, F 7/13433. Tiemann, Jugendbeziehungen, S. $306 \mathrm{f}$. 
wegen der schwierigen internationalen Lage ${ }^{153}$ tunlichst gemieden worden. Immerhin habe sich eine "weitgehende Übereinstimmung" in Wirtschaftsfragen gezeigt: „Antikapitalismus und Antimarxismus, Ablehnung des Klassenkampfgedankens und die Einsicht, daß sich der Sozialismus nur im Rahmen des nationalen Staatswesens verwirklichen läßt, war bei fast allen Gruppen zu finden." Das lebhafte Interesse der jungen Franzosen an ökonomischen und sozialen Reformen biete "entscheidende Angriffspunkte“, um den stockenden Annäherungsprozeß wieder in Schwung zu bringen, zumal der französische Sozialismus, der seine spezifische Ausprägung noch suche, dem deutschen „zweifelsohne“ näher stehen werde als etwa dem russischen. Ansonsten aber hatte Abetz kaum Gutes zu vermelden. Zwar waren einige Franzosen im Anschluß an die Tagung einer Einladung der RJF nach Saarbrücken gefolgt, wo sie den Reichsjugendberufswettkämpfen beiwohnten, von Schirach, Gauleiter Bürckel und Arbeitsminister Ley hofiert wurden und „sehr positive Eindrücke von der sozialen Aufbauarbeit des Dritten Reiches" sammelten. Doch keine Pariser Zeitung fand sich bereit, einen Reisebericht abzudrucken. Die angebotenen Artikel, hieß es, seien zu enthusiastisch und entsprächen nicht den redaktionellen Richtlinien. Abetz wertete das als „kennzeichnend für die augenblickliche Lage im französischen Pressewesen“. Auch auf anderen Gebieten mache sich „eine bewußte Sabotage der Verständigungsarbeit der französischen Jugendbünde “ durch politische und kirchliche Institutionen bemerkbar. Verschiedene Deutschlandexkursionen von Pfadfindern und Mitgliedern der Croix de Feu seien durch die Verbandsleitungen untersagt, ein nach Saarbrücken gereister Feuerkreuzler von der Sûreté Nationale überwacht, Paul Marion die weitere Zusammenarbeit seitens der Tageszeitung Le Quotidien aufgekündigt worden. Diese Vorgänge zeitigten unerfreuliche Folgen: Die Gemaßregelten, nicht selten als Vaterlandsverräter oder bezahlte HitlerAgenten verunglimpft, scheuten sich, weiterhin öffentlich für ihre Kontakte zur deutschen Jugend einzustehen. Betrübliches Fazit aus Sicht des RJF-Referenten: „Es wird Monate intensivster persönlicher Kleinarbeit bedürfen, um die deutschfranzösischen Jugendbeziehungen wieder auf den Stand zu bringen, den sie vor einem Vierteljahr hatten." 154

Nicht zum ersten Mal hatte Abetz erfahren müssen, daß sein Wirken bestimmten französischen Stellen ein Dorn im Auge war. Anfang September 1934 wollte er mit einer Karlsruher Jungvolkschar an einer Veranstaltung des Internationalen Jugendherbergsverbandes in Boissy-la-Rivière teilnehmen, danach waren Treffen mit französischen Gruppen vorgesehen. Am Grenzübergang Kehl wurden die Reisenden indes als „politisch verdächtig“ zurückgewiesen. Der in einer Aufzeichnung der Deutschen Botschaft Paris dokumentierte Vorgang ${ }^{155}$ belegt, wie

153 Am 16. März 1935 hatte Hitler die Wiedereinführung der allgemeinen Wehrpflicht und die Aufhebung der militärischen Bestimmungen des Versailler Vertrags verkündet. Die Regierungschefs von Großbritannien, Frankreich und Italien hatten dieses Vorgehen auf der Konferenz von Stresa (11.-14. April) scharf verurteilt.

154 Abetz, „Aktennotiz: Deutsch-französische Jugendaussprache Paris-Saarbrücken Ostern 1935“ (23.-26. April), Bericht vom 20. Mai, von Nabersberg mit Schreiben vom 28. Mai dem Auswärtigen Amt übermittelt; PA/AA, R 98859.

155 Aktennotiz vom 18. 9. 1934; PA/AA, Botschaft Paris 1061c. 
frühzeitig sich die französische Abwehr für Abetz interessierte; besonders seine im Sommer/Herbst 1934 intensivierten Kontakte zu prominenten Pariser Frontkämpferfunktionären schlugen sich in einer ganzen Serie von Agentenberichten nieder ${ }^{156}$. Anderseits wurde deutlich, daß seine beständig ausgebauten Beziehungen inzwischen weit genug griffen, um sich einer konsequenten Beschneidung seines Aktionsradius zu erwehren. Senatorensohn Bertrand de Jouvenel, Marc Sangnier „und andere Persönlichkeiten“ intervenierten im Quai d'Orsay erfolgreich gegen das Einreiseverbot, so daß die Jungvolkbuben schließlich mit dreitägiger Verzögerung - ohne Abetz, der anderweitig in Berlin benötigt wurde - am 9. September weiterfahren durften ${ }^{157}$. Regelmäßig wiederkehrende Verdächtigungen, ein Spion und Top-Agent Hitlers zu sein, hat Abetz auch künftig unbeschadet überstanden, so eine Veröffentlichung der von André Gide, Victor Margueritte, Oreste Rosenfeld und dem deutschen Emigranten Willy Münzenberg geleiteten Editions du Carrefour vom September 1935. Das zunächst auf Deutsch, bald darauf in französischer Übersetzung vorliegende Buch mit dem Titel Das braune Netz (Le filet brun) beleuchtete Organisationsstrukturen und Methoden der weltweit operierenden nationalsozialistischen Auslandsaufklärung und -propaganda. Ein Frankreich und seinen Kolonien gewidmetes Kapitel warnte vor friedensbewegten Avancen deutscher Frontkämpfer, die Marionetten seien und zur getarnten Kriegsvorbereitung benutzt würden, ferner vor Gaststudenten "qui étudient peu et observent beaucoup “, ferngelenkten Journalisten à la Sieburg („un opportuniste distingué") und dunklen Machenschaften parteiamtlicher Außenstellen und sonstiger deutscher Niederlassungen. Die Zahl in Frankreich tätiger GestapoSpitzel wurde auf 500 geschätzt, ein Einsatzschwerpunkt in Elsaß-Lothringen vermutet ${ }^{158}$. Als wichtige Schaltzentrale zur Koordination von Vorstößen ins Ausland galt der Stab des ,Führer'-Stellvertreters Heß, in dessen Umfeld zutreffend auch Ribbentrop und sein „enger Vertrauter" Karl Abetz [sic!] verortet wurden. Dieser dem Führungskader der HJ zugehörige Abetz, Leiter des Sohlbergkreises, Organisator von Veteranentreffen und Herausgeber einer zweisprachigen, auf Einschläferung des Gegners zielenden Revue, begnüge sich keineswegs mit Hinhaltespielchen, sondern unterstütze aktiv die geheime Wühlarbeit nationalsozialistischer Agenten in Frankreich ${ }^{159}$. Ohne näheres Eingehen auf die Zuverläs-

156 Vgl. AN, F 7/13433 und 13434 (Berichte der Sûreté Nationale aus den Jahren 1934 bis 1936) sowie Kap. III.

157 Aufzeichnung der Botschaft Paris, Aktenbestand 1061c. Ein Artikel Luchaires in Notre Temps vom 12. 9. 1934 kommt als Reflex auf diesen Vorgang in Betracht. Unter der Überschrift „Ist die Gleichheit zwischen Frankreich und Deutschland möglich?" protestierte er gegen eine Politik des übersteigerten Mißtrauens („Diese Angst, diese Feigheit, dieses Mißtrauen teilen wir nicht ${ }^{\alpha}$ ) unter Hinweis auf die verheerenden Folgen fehlender europäischer Einigung und im Vertrauen erstens auf die geistigen und wirtschaftlichen Ressourcen seines Landes, zweitens ,in die Kräfte der jungen Generationen, die, wenn sie Europa schaffen, auch Frankreich innerlich wiedererschaffen “. Zit. in DFM, OktoberNovember 1934, S. 44.

158 Le Filet Brun, aus dem Deutschen von Henri Thies, mit einem Vorwort von Berthold Jacob und Lord Listowel, Paris: Editions de la Nouvelle Revue Critique 1936, S. $90 \mathrm{ff}$., $105 \mathrm{ff}$.

159 Ebenda, S. 49 f., 123 f., 181. 
sigkeit der Dokumentation im einzelnen darf festgestellt werden, daß sie einiges Aufsehen erregte. Die erste Auflage von 300 Exemplaren war nach Informationen der Sûreté schon vor dem eigentlichen Verkaufsstart vergriffen. Mehrere tausend Bestellungen harrten der Erledigung, das Pariser Wochenjournal Vendémiaire erwarb für 10000 Francs die Zweitverwertungsrechte und druckte ausführliche Passagen ${ }^{160}$. Schwerwiegende Folgen für Abetz sind nicht zu erkennen - die Hoffnungen und taktischen Erwartungen, die führende französische Politiker und Spitzendiplomaten an seine Mittlertätigkeit knüpften, erlaubten es Staatsschützern erst im Zuge der krisenhaften Zuspitzung der Lage im Frühsommer 1939, ihm die Aufenthaltserlaubnis zu entziehen ${ }^{161}$.

Wiewohl Abetz HJ-Mitglied blieb und bis zum Gebietsführer befördert wurde ${ }^{162}$, erweiterte und verlagerte er seine Aktivitäten von Beginn an auf neue Tätigkeitsfelder. Schon wenige Wochen nach Dienstantritt bei der RJF wurde er von Hitlers außenpolitischem Berater Joachim v. Ribbentrop rekrutiert, in dessen paradiplomatischer Dienststelle verankert und mit der generalstabsmäßigen Erfassung und psychologischen Beeinflussung aller erreichbaren Bevölkerungsschichten und geistig-politischen Eliten in Frankreich betraut. Methoden und Resultate seiner Bemühungen, an denen sich die doppelbödige Beschaffenheit der nationalsozialistischen Frankreichpolitik in den Jahren 1934 bis 1939 ablesen läßt, werden in den folgenden Kapiteln ausführlich beschrieben und analysiert. Jugendbeziehungen widmete Abetz, von einigen spektakulären Veranstaltungen und Aktionen abgesehen, in jenen Jahren keine ungeteilte Aufmerksamkeit mehr, aus Zeitgründen, infolge anderer Präferenzen und gewiß auch weil ihm nicht verborgen blieb, daß die Akzeptanz der Hitlerjugend in Frankreich bescheiden war, so wie sich umgekehrt Teile der Reichsjugendführung nie recht für die westlichen Nachbarn erwärmen konnten ${ }^{163}$. Nicht selten kombinierte er künftig deutschfranzösische Jugendarbeit mit den an Umfang und Gewicht bald konkurrenzlosen Austauschbeziehungen zu ehemaligen französischen Frontkämpfern. Dieses Millionenpublikum, in dessen Reihen sich tiefempfundene Friedenssehnsucht und Bereitschaft zur Konzilianz wie nirgendwo sonst in der französischen Gesellschaft bündelten, hat er der NS-Propaganda mit einem überraschenden Schritt erschlossen, der seine eigene Karriere in neue, ungeahnte Bahnen lenken sollte.

160 Nachrichtendienstliches Material der Sûreté Nationale vom August/September 1935; AN, F 7/14714.

161 Siehe Kap. VII.

162 Vernehmung durch John Fried, 28. 5. 1947; StA Nürnberg, KV-Anklage, Interrogations, A 2.

163 Über die Gründe hierfür Tiemann, Jugendbeziehungen, S. $341 \mathrm{ff}$. 